\title{
TOOTH REPLACEMENT IN MANIDENS CONDORENSIS: BASELINE STUDY TO ADDRESS THE REPLACEMENT PATTERN IN DENTITIONS OF EARLY ORNITHISCHIANS
}

\author{
by MARCOS G. BECERRA ${ }^{1}$ (D), DIEGO POL ${ }^{1}$ (D), JOHN A. WHITLOCK ${ }^{2,3}$ (D) and \\ LAURA B. PORRO ${ }^{4}$ (D) \\ ${ }^{1}$ Consejo Nacional de Investigaciones Científicas y Técnicas (CONICET), Museo Paleontológico Egidio Feruglio, Fontana 140, Trelew, Chubut U9100GYO, \\ Argentina; mbecerra@mef.org.ar, dpol@mef.org.ar \\ ${ }^{2}$ Biology Department, Mount Aloysius College, Admiral Peary Highway 7373, Cresson, PA 16630, USA; jwhitlock@mtaloy.edu \\ ${ }^{3}$ Section of Vertebrate Paleontology, Carnegie Museum of Natural History, 4400 Forbes Avenue, Pittsburgh, PA 15213, USA \\ ${ }^{4}$ Centre for Integrative Anatomy, Department of Cell \& Developmental Biology, University College London, Gower Street, London, WC1E 6BT, UK; \\ l.porro@ucl.ac.uk
}

Typescript received 4 March 2020; accepted in revised form 2 July 2020

\begin{abstract}
Dental replacement in Heterodontosauridae has been debated over the last five decades primarily on indirect evidence, such as the development of wear facets and the position of erupted teeth. Direct observation of unerupted teeth provides unambiguous data for understanding tooth replacement but this has been done only for Heterodontosaurus and Fruitadens. This study addresses dental replacement in Manidens condorensis based on the positioning of functional and replacement teeth using microcomputed tomography data, differential wear along the dentition and the differences in labiolingual/apicobasal level of functional teeth. Dental replacement in Manidens condorensis was continuous in an anterior-to-posterior wave pattern, with asynchronous tooth eruption and the addition of new teeth posteriorly to the toothrow during ontogeny. Manidens shows the first evidence of dental replacement for the large dentary caniniform in Heterodontosauridae, which possibly had replacement timing distinct from the cheek dentition.
\end{abstract}

Newly erupted teeth imbricate in a mesial cavity-distal crown base relationship during eruption, so that imbrication of the midposterior dentition remains unaltered during tooth replacement. The presence/absence of a small caniniform tooth in the D3 position of several specimens suggests possible intraspecific dimorphism in Manidens. On longitudinal sections of isolated crowns the histological features such as Howship's lacunae and odontoclast spaces are similar in size to extant reptiles. The differential wear decreasing posteriorly and hypothetical Z-spacing below 2.3 in Manidens are similar to basal ornithischians. Tooth replacement in Heterodontosauridae (and other early ornithischians) provides key information for understanding the dynamics of jaw function and craniomandibular specialization to herbivory.

Key words: Ornithischia, Heterodontosauridae, tooth replacement, 3D reconstruction, intraspecific dimorphism, dentition.
THE development of precise occlusion and tooth wear is a recurrent trend that has improved chewing efficiency in different herbivorous lineages (Janis \& Fortelius 1988; MacFadden 2000; Kaiser et al. 2013; Madden 2014; Erickson et al. 2016). The consequences of extensive tooth wear can be overcome by the appearance of high-crowned (hypsodont) dentitions or high rates of tooth replacement (D’Emic et al. 2013; Erickson et al. 2016). High replacement rates have been inferred for many dinosaur clades, including polyphyodont dentitions (i.e. dentitions with continuous tooth replacement) with spaced teeth as in non-cerapodan ornithischians, non-hadrosaurid dryomorphs and early ceratopsians (Norman \& Weishampel 1985; Weishampel \& Norman 1989; Sander 1997; Norman 2004; Tanoue et al. 2009; Strickson et al. 2016). The condition of high replacement rates alongside tightly packed dental batteries that form a continuous grinding surface is a derived stage of polyphyodonty that appeared independently in ceratopsids, hadrosaurids, and some neosauropods (Dodson et al. 2004; Horner et al. 2004; Sereno \& Wilson 2005; Bell et al. 2009). Within Heterodontosauridae (and convergently shared with Therizinosauria; Button 
et al. 2017), more derived species had polyphyodont highcrowned and tightly packed dentitions with low replacement rates, mixing two different evolutionary stages that represent a novel adaptive path to increased herbivory in the Ornithischia (Norman et al. 2011; Sereno 2012). The above-mentioned cases indicate that different clades of herbivorous dinosaurs developed different adaptations to herbivory. However, there is still a lack of understanding of dental evolution in dinosaurs due to the small number of studies of species representing early adaptive stages to herbivory (Stirton 1947; Erickson et al. 2016; Strickson et al. 2016; Button et al. 2017). Furthermore, studies on tooth replacement in early ornithischians are rare despite their importance for understanding the evolution of herbivory in this diverse and successful clade (Sciscio et al. 2017; Chen et al. 2018).

The middle-late Toarcian to Aalenian-Bajocian Cañadón Asfalto Formation (Cúneo et al. 2013) has yielded one of the most important continental vertebrate faunas from the early Jurassic of the southern hemisphere (Bonaparte 1979; Rauhut et al. 2001; Escapa et al. 2008; Pol \& Rauhut 2012). The record of ornithischians from this unit is so far limited to the heterodontosaurid Manidens condorensis (Pol et al. 2011); a second heterodontosaurid species lacking diagnostic features (Becerra et al. 2016); and an isolated ungual referred to Cerapoda (Rauhut \& Lopez-Arbarello 2008). Manidens is the most complete early Jurassic ornithischian from South America and one of the most complete heterodontosaurids. The holotype material MPEF-PV 3211 of the small-sized heterodontosaurid Manidens condorensis, which includes cranial and postcranial remains, preserves a posteriorly incomplete right maxillary dentition and a nearly complete dentary dentition in both dentaries ( $\mathrm{Pol}$ et al. 2011). Regardless of its preservation, the maxillary and dentary dentitions in known specimens range between 10 and 13 tooth positions, a low count that is characteristic for Heterodontosauridae ( $\mathrm{Pol}$ et al. 2011; Becerra et al. 2014, 2018). The morphology of the maxillary dentition was characterized based on MPEF-PV 3211 and 3809 by Becerra et al. (2018) as symmetric diamondshaped teeth with a low number of denticles, enlarged labial and lingual crests in the crown bases (cingular mesial and distal entolophs and ectolophs), with both entolophs in a V- to Z-shaped disposition and bearing denticles/serrations. The morphology of the dentary dentition as detailed by Pol et al. (2011) and Becerra et al. (2014), is based on MPEF-PV 3211 and isolated teeth, and consists of an enlarged caniniform in the first tooth position and symmetrical diamond-shaped ('handshaped') postcaniniform teeth. Although these dentitions show a strongly contrasting morphology, they share a height-width proportion heterodonty along the toothrow, the presence of a mesial cavity in teeth from the midposterior toothrow that allows close-packing, thickened enamel in the cutting edges of denticles (although only dentary teeth bear crenulated edges), and the development of apical and basal wear facets that indicate a novel and complex pattern of tooth-tooth occlusion, making this taxon unique in terms of its adaptations to herbivory (Becerra et al. 2014, 2018). Here we describe tooth replacement inferred for this taxon based on microcomputed tomography $(\mu \mathrm{CT})$ of its dentition and interpret its significance for the early evolution of heterodontosaurids and ornithischians.

Institutional abbreviations. BP, Bernard Price Institute for Palaeontological Research, Johannesburg, South Africa; IVPP, Institute of Vertebrate Paleontology and Paleoanthropology, Beijing, China; MPEF, Museo Paleontológico Egidio Feruglio, Trelew, Chubut, Argentina; NHMUK, The Natural History Museum London, UK; NM, Nazionale Museum, Bloemfontein, South Africa; SAM, Iziko South African Museum, Cape Town, South Africa; YPM, Peabody Museum of Natural History, Yale University, New Haven, USA.

\section{MATERIAL AND METHOD}

\section{Material}

All the fossil material used in this study is housed in the vertebrate palaeontology collection of the MPEF in Trelew (Chubut), Argentina. All specimens included in this study were found in the Queso Rallado locality except for MPEF-PV 3808, which was found in the Frenguelli fossil site. Both localities belong to the lower levels of the Cañadón Asfalto Formation (Pol et al. 2011; Cúneo et al. 2013; Becerra et al. 2014, 2018, Becerra \& Pol 2020).

Specimen MPEF-PV 3211. The preserved elements on this specimen consist of at least $80 \%$ of the cranial bones, scattered vertebrae representing all axial regions (cervical, dorsal and caudal vertebrae, and the complete sacral region), the left scapula and coracoid, an almost complete pelvic girdle, and rib fragments ( $\mathrm{Pol}$ et al. 2011; Becerra et al. 2014). The specimen corresponds to the holotype material of Manidens condorensis, as defined by Pol et al. (2011).

Specimen MPEF-PV 3808. This new specimen consists of partially exposed fossil remains at the face and back of a lacustrine tuffaceous shale rock fragment, corresponding to a right dentary, at least five dorsal vertebrae, most of a scapula, and other unidentified elements inside the rock (see below). The poor preservation of the fossil prevents its 
mechanical separation from the rock. MPEF-PV 3808 was found at the Frenguelli fossil site, $15 \mathrm{~km}$ south of Cerro Cóndor village and stratigraphically located at the lower levels of the Cañadón Asfalto Formation (Escapa et al. 2008; Cúneo et al. 2013). This locality has produced abundant plant remains, and sediments sampled $10 \mathrm{~m}$ above the fossiliferous horizon have been dated as middle-late Toarcian (178.766 \pm 0.092 Ma; Cúneo et al. 2013). MPEF-PV 3808 is here referred to the species Manidens condorensis based on the following shared autapomorphies of the dentary dentition: asymmetric arrangement of denticles and a mesial concavity or cavity in midposterior teeth ( $\mathrm{Pol}$ et al. 2011); mesial denticulate margin c. $60 \%$ of the length of the distal margin (Becerra et al. 2014); and denticles with crenulated edges (Pol et al. 2011). Additional features shared between teeth of this specimen and the dentary dentition of Manidens condorensis include: the presence of one to two denticles mesially and four to six distally in dentary teeth; and a notably heterodont dentition in terms of size and shape including the presence of a large caniniform in the first tooth position (Becerra et al. 2018, and references therein).

Specimen MPEF-PV 3809. The specimen consists of a complete left maxilla with 10 tooth positions and eight teeth, part of the anterior process of the lacrimal and the distalmost portion of the posterodorsal process of the premaxilla, with the latter two fragmented bones contacting the ascending process of the maxilla. This specimen was associated to the species Manidens condorensis by Becerra et al. (2018) and is based on the unique features of the maxillary dentition shared between this specimen and the holotype MPEF-PV 3211.

Isolated teeth. The sectioned specimens MPEF-PV 10862a and $\mathrm{b}$ (both from the same isolated dentary tooth) and MPEF-PV 10823 (isolated maxillary tooth) were associated with the species Manidens condorensis based on their shared dental features with those in the holotype and referred specimens by Becerra \& Pol (2020). Other isolated dentary teeth (MPEF-PV 3814, MPEF-PV 3816, MPEF-PV 3815, MPEF-PV 1719, MPEF-PV 3811, MPEFPV 1786, MPEF-PV 3812, MPEF-PV 3813 and MPEF-PV 10866) mentioned elsewhere in the text were associated to Manidens condorensis by Becerra et al. (2014) and Becerra et al. (2018, online resource 1) based on shared dental morphologies.

\section{Procedure}

Sectioning of isolated maxillary and dentary teeth was conducted following the standardized methodology of
Sander (1999) (Becerra \& Pol 2020). Scanning electron microscopy (SEM) was carried out using a Jeol JSM-6460 with backscattered electron detector. CT scanning of MPEF-PV 3808 was conducted using a helical tomographic GE model CTe. The $\mu \mathrm{CT}$ scanning of specimens MPEF-PV 3211 and MPEF-PV 3809 was conducted using a GE phoenix nanotom ${ }^{\circledR} \mathrm{m}$. Segmentation and 3D reconstruction were performed using 3DSlicer version 4.3.0 (Fedorov et al. 2012).

The anatomical terminology used in the orientation and description of the teeth follows Becerra et al. (2018). Two models of dental replacement corresponding to Zahnreihen theory are discussed for amniotes: (1) the wave stimulus theory; and (2) the zone of inhibition theory (Whitlock \& Richman 2013). Edmund (1960, 1962, 1969) explained tooth replacement as the result of successive extrinsic wave stimuli of toothgrowing activity that originate in the anterior dental mesenchyme and are transmitted posteriorly, in which the time interval between successive stimuli defines the rate of tooth replacement and determines the observed pattern (Berkovitz \& Shellis 2016). The zone of inhibition theory suggests that a developing tooth emits a signal into the mesenchyme that inhibits the development of neighbouring teeth within a certain radius; once it erupts the dental lamina is no longer inhibited and starts developing adjacent replacement teeth (Osborn 1971; Whitlock \& Richman 2013). Subsequent research indicated that deviations of these models or more complex patterns of replacement may occur in reptiles (Whitlock \& Richman 2013; Berkovitz \& Shellis 2016; Greico \& Richman 2018). The replacement pattern of Manidens condorensis closely resembles that described under the wave stimulus theory and is comparable to that in Heterodontosaurus (SAM-PK-K1334), in which the definition of replacement waves as series of teeth in decreasing stages of development was useful for understanding the spatial arrangement of successive dental families in a toothrow (Norman et al. 2011). Thus, a similar successive series of decreasing stages ordered in a wave pattern was assumed in this description of Manidens condorensis. Previous research in reptiles and basal ornithischians addresses the apparent direction of replacement waves externally and relates this to Z-spacing (or the average of functional teeth per replacement series; Edmund 1960, 1969; Demar 1972; Berkovitz 2000). In a toothrow with a Z-spacing higher than 2, the direction of the replacement wave appears to be anteriorly directed, whereas a value smaller than 2 leads to a posteriorly directed replacement wave (Edmund 1969). The ordering of functional teeth, Z-spacing and apparent direction of replacement are also discussed for Manidens. 


\section{RESULTS}

\section{Maxillary dentition}

Specimen MPEF-PV 3211. The holotype specimen of Manidens condorensis MPEF-PV 3211 preserves only the right maxilla (Fig. 1), which bears the first eight functional tooth positions, a reduced tooth count due to the lack of preservation of the caudal region of the maxilla (Becerra et al. 2018). If considering the opposing dentary dentition (up to 11 functional teeth), the maxillary dentition of MPEF-PV 3211 possibly had at least 10-11 functional teeth. The $3 \mathrm{D}$ reconstruction allows the identification of different stages of replacement in seven of the eight tooth positions preserved (Fig. 2A, B). An empty small alveolus completely filled with spongy bone and a root fragment are the only evidence of a small M1 tooth, anterior to the beginning of the preserved toothrow, which would have been shed and was not replaced (Becerra et al. 2018; Fig. 2H). The absent M1 and the following four maxillary teeth that are laterally exposed (Fig. 1) have their roots associated with dental or tooth crypts (i.e. the bony space of either jaw containing a developing tooth, whereas the dental alveolus/alveoli are the cavities or sockets in which the roots of functional teeth are embedded), while the presence of these in the midposterior toothrow is unknown due to the damaged condition of the maxilla (Becerra et al. 2018, online resource 1; Fig. 2). All the tooth crypts preserve tooth germs (Fig. 2C-G), except one close to the tip of the root of M2 that is empty (Fig. 2C, D). The relative position of all the tooth crypts with the functional teeth might be slightly affected by damage, but as preserved these are positioned anterior to the first preserved maxillary tooth (possibly related to M1), dorsal to the root tip of M3, and dorsal and slightly lateral to the tips of the roots of M4 and M5 (Fig. 2). More posteriorly, a replacement tooth is located within a collapsed tooth crypt slightly posterolaterally to M7 and contacting the root of M8, which might be related to M7 but was diagenetically displaced (Fig. 2A, B). M8 shows an extensive resorption area at the posteromedial half of its crown base and root, adjacent to the posteriormost replacement tooth preserved (Fig. 2A, B). For the anterior dentition, the differential development of wear as indicator of differences in lifespan of functional teeth adds additional information regarding tooth replacement (Table 1 ). The slightly concave and wide lingual wear facet of M2 and the lack of extensive wear at M3, although both feature polished marginal denticles and less extensive labial facets (M2M4; Becerra et al. 2018, online resource 1), indicate that M2 was possibly older than M3, supporting an anteriorto-posterior wave replacement pattern. Wear facets cannot be identified at tooth positions M5-M8 with the available data.

The positioning of replacement teeth and of wear development in the maxillary dentition of MPEF-PV 3211 suggests a replacement pattern possibly including five different replacement waves (Fig. 2I). In an anteroposterior direction, the first three tooth crypts seem to pertain to the first replacement wave. The second series is formed by the absent M1 (as the last tooth changed), the tooth positions M2-M3 (evidenced by wear being more developed at M2), and the remaining two tooth crypts (Fig. 2I). Two other replacement waves are identified in the midposterior dentition, and M8 is the only representative of the fifth replacement series (Fig. 2I). The functional teeth of all the replacement series are arranged in a 2-3-1-1 sequence. Unfortunately, the taphonomic displacement of teeth and the possibility that the dentition is not complete complicate inference of the external direction of replacement waves considering odd and even tooth positions (see Discussion).

Two additional resorption pits adjacent to the lateral face and between the roots of M3 and M4 were recognized (Fig. 2A-D, G, H). The resorption pit more dorsally placed affected only the bone adjacent to the roots, whereas both the bone and the root were affected by the more ventrally positioned pit. Their subcircular shape supports a physiological origin, and their presence between M3 and M4 but at the opposite side of the toothrow from where new replacement teeth are formed indicates that it is more likely that these are related to a palaeopathological process of external resorption occurring at these tooth positions (Fig. 2A, B).

Specimen MPEF-PV 3809. Although some bones are incomplete or missing, this specimen preserves the complete maxillary toothrow (not damaged as occurs in specimen MPEF-PV 3211), which is composed of 10 tooth positions (Fig. 3E, F), with two roots anteriorly (the smaller one partially reabsorbed) and eight teeth in excellent preservation (Becerra et al. 2018). The tooth count in MPEF-PV 3809 is closer in number to the assumed maxillary dentition and the known postcaniniform dentary dentition of MPEF-PV 3211, and shows only slight differences in size with the maxilla of the mentioned specimen that are mainly related to its damaged posterior region. The fossil remains represented by MPEF-PV 3809 and MPEF-PV 3211 might correspond to similarly sized individuals.

Information from $\mu \mathrm{CT}$ allows identification of three empty spaces at the base of the premaxillary process, which are collapsed and confluent to each other anterior and dorsal to the first two tooth positions, and two replacement teeth posteriorly (Fig. 3E, F). The rounded 

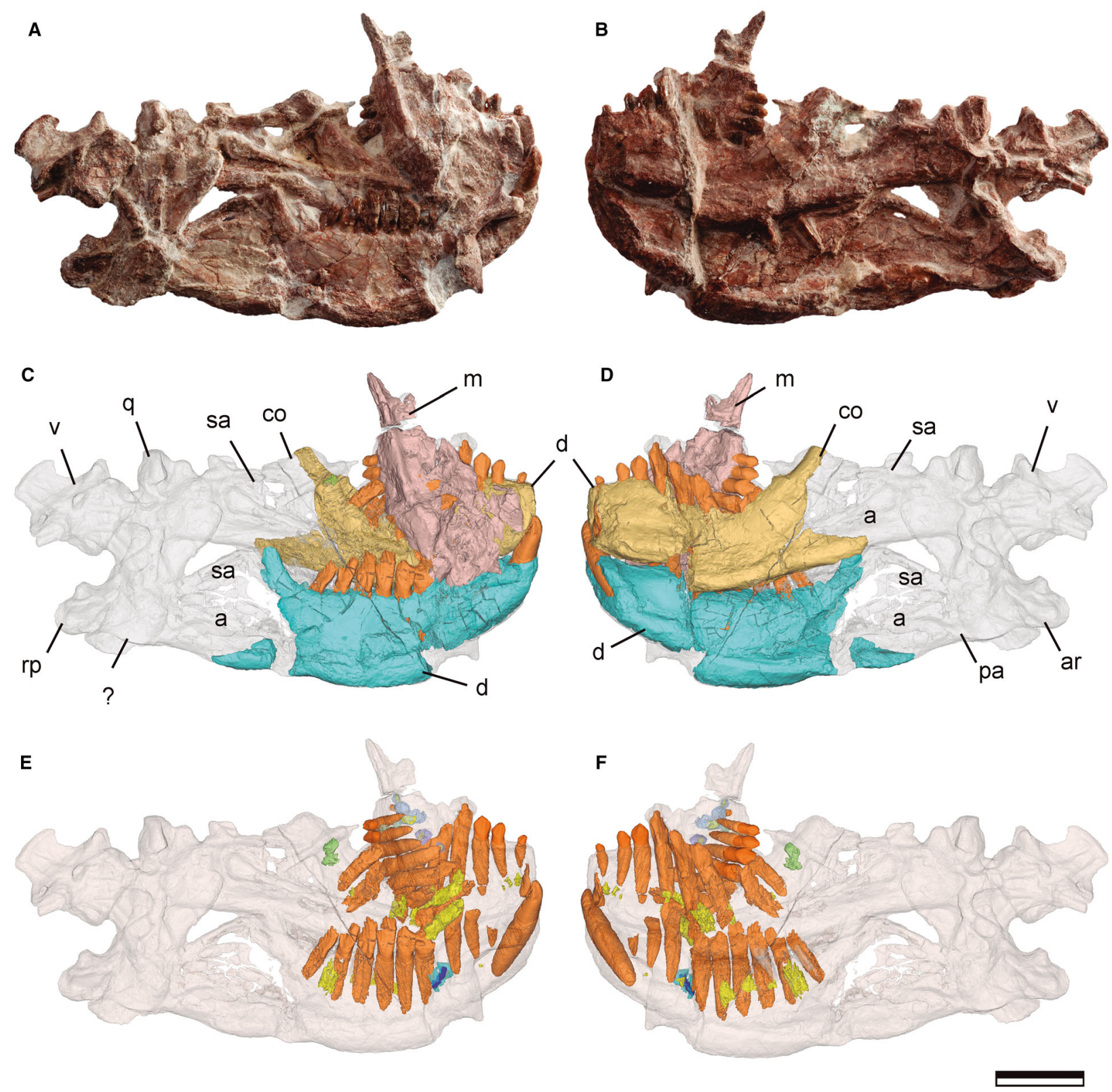

FIG. 1. Manidens condorensis specimen MPEF-PV 3211, craniomandibular remains with preserved dentition (modified from Becerra et al. 2018). A-F, specimen and $3 \mathrm{D}$ reconstruction based on $\mu \mathrm{CT}$ information in right (A, C, E) and left (B, D, F) views. C-F, 3D reconstructions highlight the maxilla (pink), the right (sky blue) and left (gold) dentaries, the functional (orange) and replacement teeth (yellow), the replacement caniniform (dark blue), maxillary and dentary tooth crypts (transparent blue), and the unerupted left D11 tooth (green). Abbreviations: ?, unknown element; a, angular; ar, articular; co, coronoid process of the dentary; d, dentary; m, maxilla; pa, prearticular; q, quadrate; rp, retroarticular process; sa, surangular; v, vertebra. Scale bar represents $1 \mathrm{~cm}$.

shapes of these empty chambers indicate that they probably correspond to tooth crypts that lack tooth germs, as occurring in the comparable dentition of MPEF-PV 3211 (Fig. 2A, B). The anterior position of the first two tooth crypts prevents correlation of them with a tooth position, whereas the most posterior crypt may relate to the M1 position, given that it is located dorsal to it. Although only two replacement teeth and another three tooth crypts are identified in MPEF-PV 3809 (Fig. 3), other lines of evidence (differential development of wear, the alveolar retraction and the labiolingual offset of teeth in occlusal view) help elucidate the possible replacement pattern for MPEF-PV 3809. The expected differential wear tendency decreasing posteriorly in the context of 

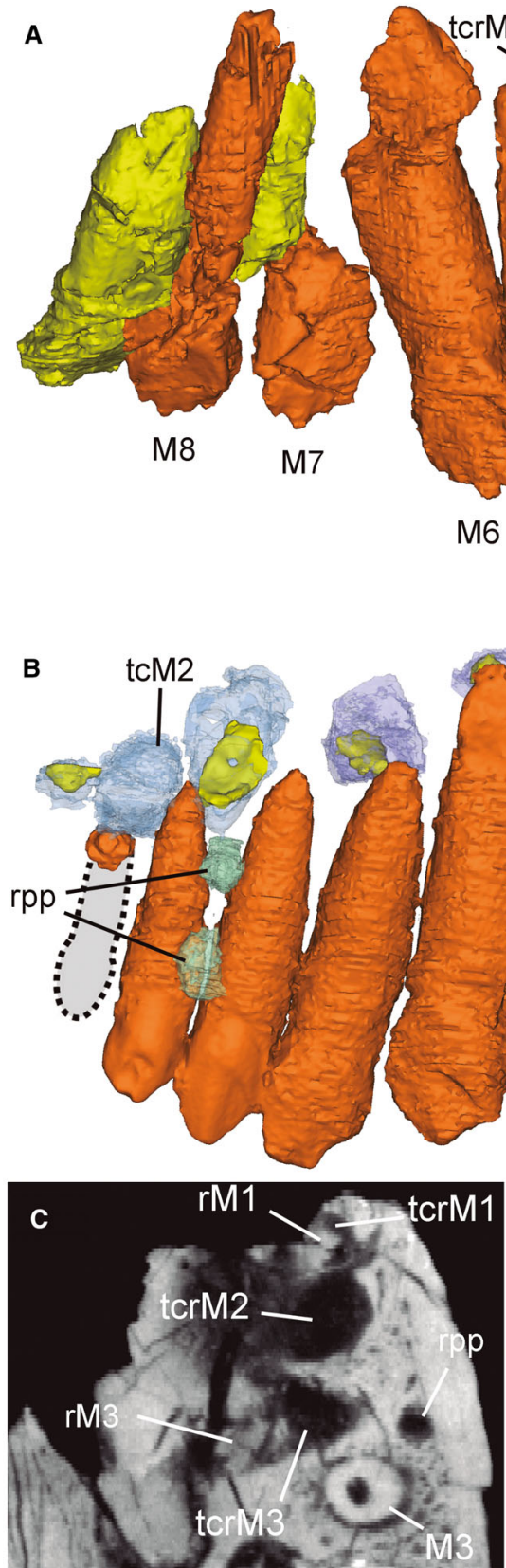

tcrM5 tcrM4 tcrM3
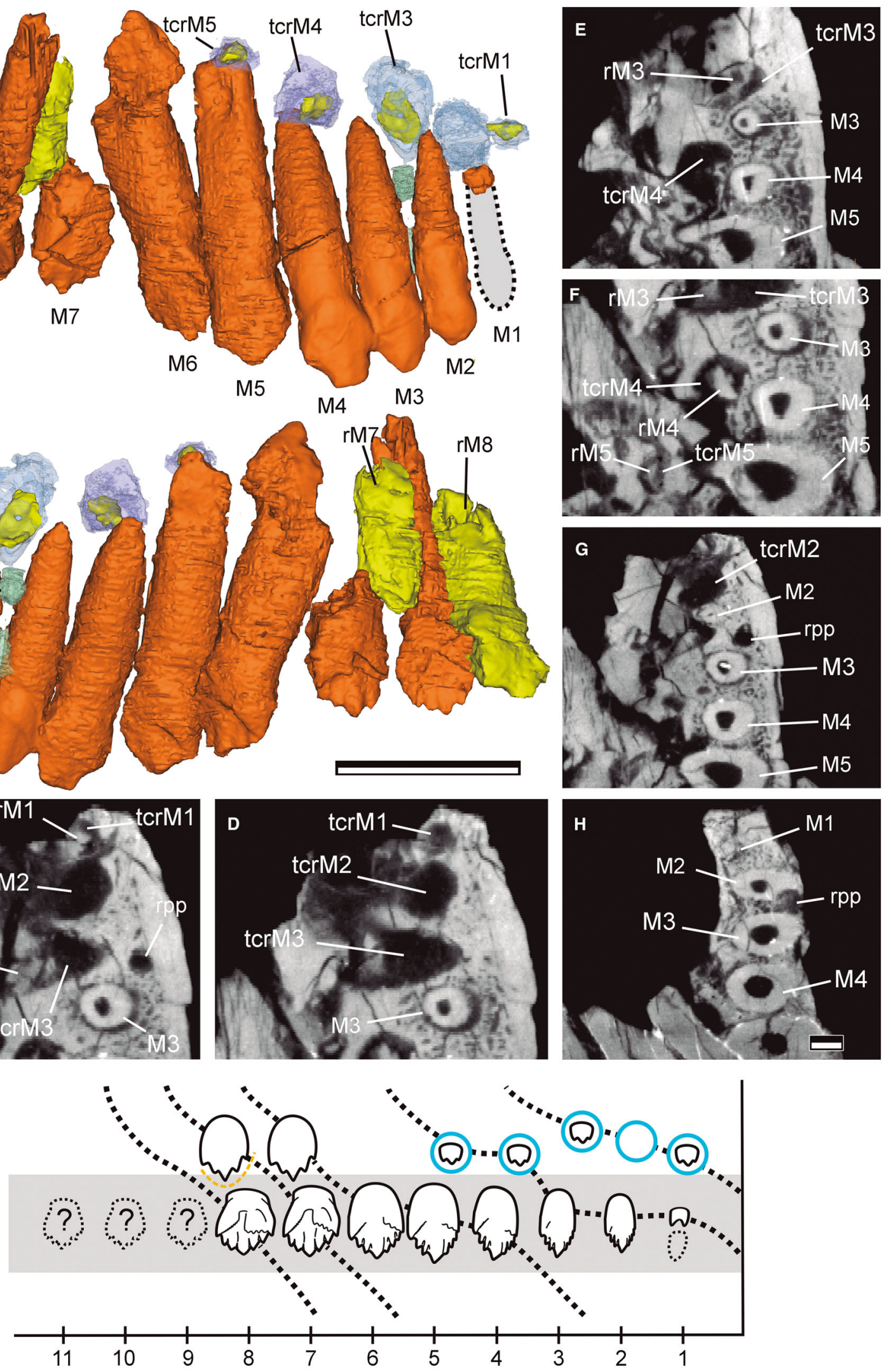
FIG. 2. Manidens condorensis specimen MPEF-PV 3211, right maxillary dentition (modified from Becerra et al. 2018). A-B, 3D reconstructed dentition based on $\mu \mathrm{CT}$ in: $\mathrm{A}$, lateral; $\mathrm{B}$, medial view; functional (orange) and replacement (yellow) teeth; dotted lines indicate the missing $\mathrm{M} 1$ based on its fragmented crown base (A-B, I); colour differences in tooth crypts (transparent lighter and darker blue) represent different replacement series, with pathological resorptions (transparent green). C-H, successive sagittal $\mu \mathrm{CT}$ sections of the maxilla showing the positioning of tooth crypts (with their corresponding tooth germs) and the pathologic resorption processes. I, diagram of hypothetical replacement series (thick dotted lines) acting in the maxillary dentition (tooth positions on the $\mathrm{x}$-axis, functional teeth in the grey area), anterior was standardized at right, the tooth crypts are drawn as blue circles (with and without tooth germs), segmented yellow lines indicate root resorption, early and later tooth germs are drawn with different sizes and shapes, hypothetical posterior dentition in dotted lines. Abbreviations: M1-M8, functional tooth positions in order from the first to the eighth tooth; rM7-rM8, replacement teeth for tooth positions M7 and M8; rpp, resorption pathologic process; tcrM1-tcrM5, tooth crypts associated with positions M1-M5. Scale bars represent: $5 \mathrm{~mm}(\mathrm{~A}, \mathrm{~B}) ; 1 \mathrm{~mm}(\mathrm{C}-\mathrm{H})$.

replacement waves in an anterior-to-posterior direction is observed in tooth positions M5-M7, whereas wear increases posteriorly from M3 to M5 and from M7 to M10 (Table 1, Becerra et al. 2018; Fig. 3D, F). The increase in wear area posteriorly (instead of anteriorly) in tooth positions M3-M5 could be influenced by the differences in height-width proportions and increased size of the teeth along the toothrow (with mainly apical wear), and that in tooth positions M8-M9 by the increase in prominence of the lingual cingular entolophs posteriorly (with wear mainly cingular; Becerra et al. 2018). The alveolar level in medial view provides information about a possible replacement pattern for the dentition in MPEFPV 3809, inferring that more retracted alveoli belong to recently erupted teeth. The alveolus at position M5 is more retracted basally than in M6 (M5 may possibly be the last functional tooth of its replacement series). Similarly, the alveolar level of M7 is more retracted than M6 and M8, and similarly for M9 if compared with M8 and M10 (Becerra et al. 2018, online resource 1; Fig. 3A, B). It is likely that the ends of successive replacement waves also occur at M7 and M9. This observation is consistent with the offset of teeth in occlusal view (Becerra et al. 2018, online resource 1). The most anterior preserved teeth are medially deflected up to M5; between M5 and M7 the toothrow becomes laterally oriented up to M7, and finally it extends parasagittally from M8 to M10. This offset in occlusal view is similar to that in Lanasaurus described by Gow (1975).

At least four replacement waves were possibly active in MPEF-PV 3809 (Fig. 3G). The labiolingual offset of the dentition in occlusal view and retraction of the alveolar level support this inference, while the differential development of wear related to the lifespan of teeth and replacement waves applies only to tooth positions M6-M7 (wear area decreasing posteriorly). The anteriorly positioned tooth crypts, due to their location in the maxilla, surely relate to tooth position M1 (and possibly M2), although it is difficult to discern if M1 and M2 are from the same replacement series; if the tooth crypts correspond to the same or different replacement waves; and how these relate to the general pattern of replacement. The exact relationship of M1 and M2 and the anterior tooth crypts to the successive teeth cannot be determined from the available evidence and is taken as inconclusive. The M3-M5 positions can be identified as the first well-defined replacement series, followed by M6-M7 in the second and M8M9 in the third series, whereas the tooth in position M10 represents the last replacement series. The series of dental replacement imply a succession of ?-3-2-2-1 functional teeth per series, with the two replacement teeth in development in the maxilla related to the second and third series (Fig. 3G).

\section{Dentary dentition}

Specimen MPEF-PV 3211. The preservation of the dentaries exposes different regions of the dentition, but $\mu \mathrm{CT}$ confirms that the dentitions in both dentaries are complete (Pol et al. 2011; Becerra et al. 2014; Fig. 4). The unpreserved region anterior to the enlarged caniniform in both dentaries does not confirm or reject the existence of a pre-caniniform rudimentary tooth for Manidens, which is present in Fruitadens, possibly Echinodon and specimen NHMUK A100 in Heterodontosauridae (Butler et al. 2012; Sereno 2012). The right dentary, incomplete anterior to the caniniform and fractured in the middle, exposes the enlarged caniniform and six teeth at the midposterior dentition (Fig. 1), with three additional teeth hidden by the maxilla and the left dentary, and discovered using $\mu \mathrm{CT}$ (Fig. 4A, B). All functional teeth are exposed in the left dentary, with a root fragment of the enlarged caniniform and eight postcaniniform teeth that are more damaged than in the right dentary (Fig. 4C, D). The enlarged caniniform (D1) in the right dentary showing a plane wear facet with polished limits at its apex was described by Pol et al. (2011) and Becerra et al. (2014). On $\mu \mathrm{CT}$ the root of the caniniform D1 is slightly longer than its crown and both are separated by a basal constriction (Fig. 4A, B). The roots of cheek teeth of Manidens are long and closed at their tips as in other 
TABLE 1. Wear development in teeth of the preserved tooth-bearing bones of Manidens condorensis

\begin{tabular}{|c|c|c|c|c|c|c|c|c|c|c|c|}
\hline & TP 1 & TP 2 & TP 3 & $\mathrm{TP} 4$ & TP 5 & TP 6 & TP 7 & TP 8 & TP 9 & TP 10 & TP 11 \\
\hline $\begin{array}{l}\text { MPEF-PV } \\
3211 \text { maxilla }\end{array}$ & $?$ & Moderate & Mild & $?$ & $?$ & $?$ & $?$ & $?$ & - & - & - \\
\hline $\begin{array}{l}\text { MPEF-PV } \\
3808 \text { maxilla }\end{array}$ & $?$ & $?$ & Moderate & Extensive & Extensive & Extensive & Mild & Mild & Moderate & $\begin{array}{r}\text { Moderate/ } \\
\text { extensive }\end{array}$ & \\
\hline $\begin{array}{l}\text { MPEF-PV } 3211 \\
\text { right dentary }\end{array}$ & Mild & $?$ & - & $?$ & $?$ & $?$ & $?$ & $?$ & Without wear & Extensive & Mild \\
\hline $\begin{array}{l}\text { MPEF-PV } 3211 \\
\text { left dentary }\end{array}$ & $?$ & $?$ & - & Mild & Moderate & ?Mild & $?$ & $?$ & Without wear & $?$ & - \\
\hline
\end{tabular}

$\mathrm{TP}$, tooth position; ? development of wear unknown; - tooth position missing or not preserved.

Heterodontosauridae (Butler et al. 2012; Sereno 2012), indicating that the enlarged caniniform had limited growth and the longest root in the dentition, but proportionately longer roots relative to their crowns are present in D7-D8 tooth positions (Fig. 4A, B). In addition, a large cylindrical replacement tooth in a partially collapsed tooth crypt can be spotted anterolateral to the root of the right D6 tooth (Fig. 4A, B, G, H). The activity related to the development of this replacement tooth affected the neighbouring root of D6, which bears a laterally facing resorption region. The location of the root resorption for D6 (laterally instead of medially), the overall shape and the oblique orientation of the major axis of this replacement tooth to the ventral margin of the dentary (instead of perpendicularly as other replacement cheek teeth) indicate that this element corresponds to a replacement tooth for the caniniform D1. No other heterodontosaurid presents evidence of tooth replacement for the enlarged caniniform; thus, the replacement caniniform in the right (but not the left) dentary of MPEF-PV 3211 represents novel information for the lineage.

The tooth at the position D2 is exposed in the left dentary but is missing its crown on the right; both show similarly sized roots in the 3D reconstructions (Fig. 4). There is a slight postcaniniform diastema between the caniniform tooth D1 and the first postcaniniform tooth D2 as wide as an alveolus in both dentaries, and with compact bone at the alveolar region (Fig. 4A-D), a feature never described for Manidens but present in most heterodontosaurids with known dentary dentition (Sereno 2012). A similar empty space exists between D2 and the following postcaniniform tooth as wide as an alveolus in both dentaries (Fig. 4A-F). Such a space is also observed in Fruitadens where the D2 tooth position is surrounded anteriorly and posteriorly by compact bone (Butler et al. 2012, fig. 4N). However, in MPEF-PV 3211, and contrasting with Fruitadens, the bone type filling the alveolar region between D2 and the next preserved tooth is spongy instead of compact in both dentaries, and the contact between compact and spongy bone forms a subcircular shape (as shaping a closed alveolus; Fig. 4E, F). However, there are no remnants of roots or replacement teeth at this region, showing a depressed lateral surface in the anteroposterior direction on the dentary (as if there had never been a tooth). The presence of spongy bone shaping an empty alveolus in both dentaries implies a hypothetical tooth position (D3) rather than a diastema (as in Fruitadens), which possibly fell out and was not replaced. In contrast, the absence of any root fragment or replacement teeth (in either of the dentaries) may imply that this tooth position may have never been occupied. The evidence indicates that the D2 position is as close to the rest of the postcaniniform dentition for Manidens as in other heterodontosaurids excluding Fruitadens (Zheng et al. 2009; Norman et al. 2011; Sereno 2012) but at least in MPEF-PV 3211, the D3 position was not developed or, if it was, the tooth was lost and never replaced (see MPEF-PV 3808). The right dentary has 11 functional

FIG. 3. Manidens condorensis specimen MPEF-PV 3809, left maxilla with fragments of other rostral elements and most of its dentition preserved (modified from Becerra et al. 2018). A-F, specimen and 3D reconstructions in lateral (A, C, E) and medial (B, D, F) views. C-F, the preserved functional (orange) and replacement (yellow) teeth, and tooth crypts (transparent blue). E-F, dotted lines indicate the alveolar level. G, diagram of the hypothetical replacement series (thick dotted lines) acting in the maxillary dentition (tooth positions on the $\mathrm{x}$-axis, functional teeth in the grey area), anterior was standardized at right, tooth crypts as blue circles, root resorption as dashed yellow lines, the missing M1-M2 crowns drawn with thin dotted lines over a fragmented crown base. Abbreviations: aaf, accessory antorbital fenestra; af, antorbital fenestra; 1, lacrimal bone fragment; m, maxilla; M1-M10, first to 10th functional tooth positions; ppm, maxillary anterior process for the premaxilla; pmx, premaxillary bone fragment; rM8 and rM10, replacement teeth for tooth positions M8 and M10; snf, subnarial foramen; tcrM?, tooth crypt with unknown association to the tooth row; tcrM1 tooth crypt associated with position M1. Scale bars represent: $1 \mathrm{~cm}(\mathrm{~A}-\mathrm{D}) ; 5 \mathrm{~mm}(\mathrm{E}, \mathrm{F})$. 

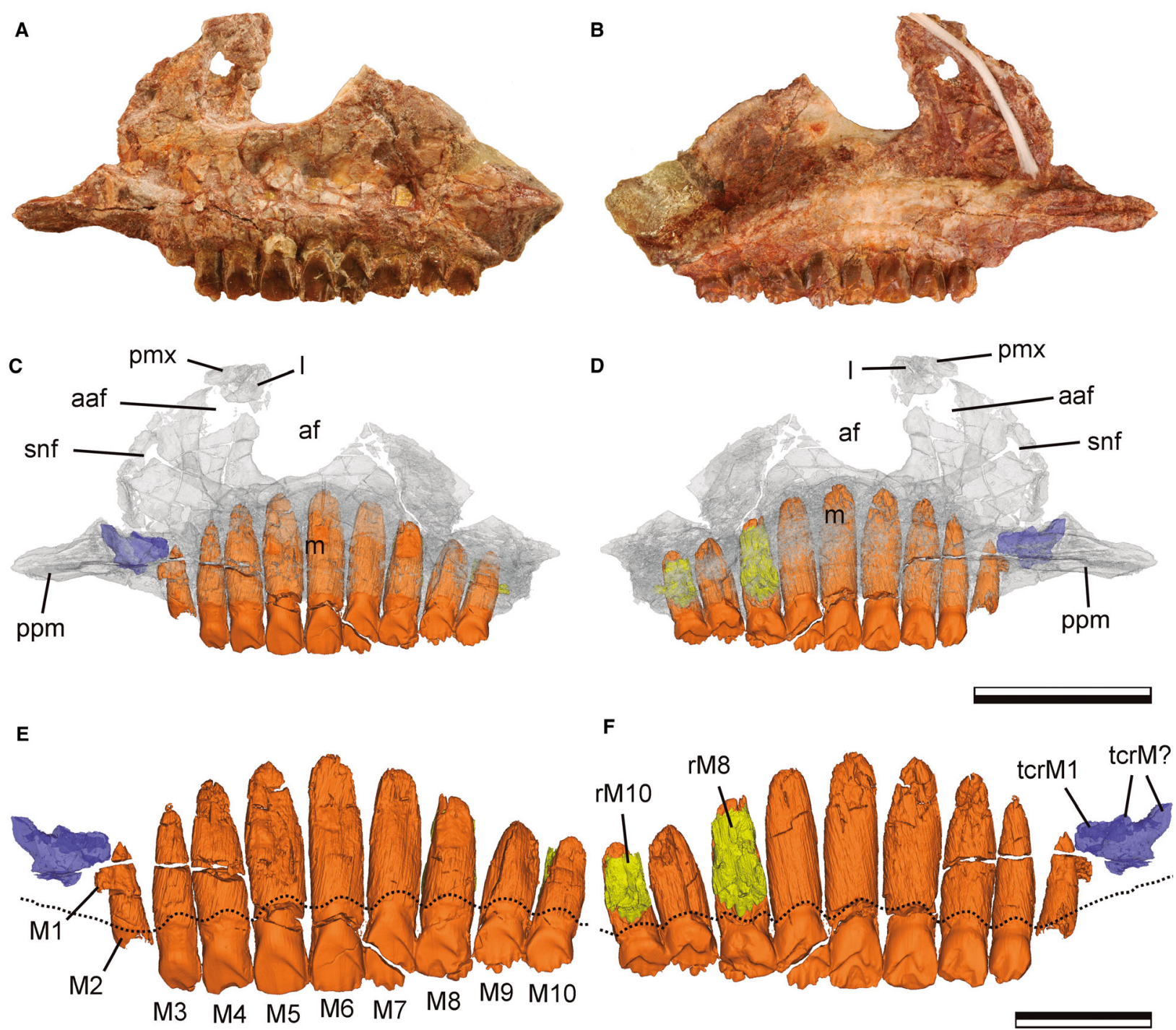

G

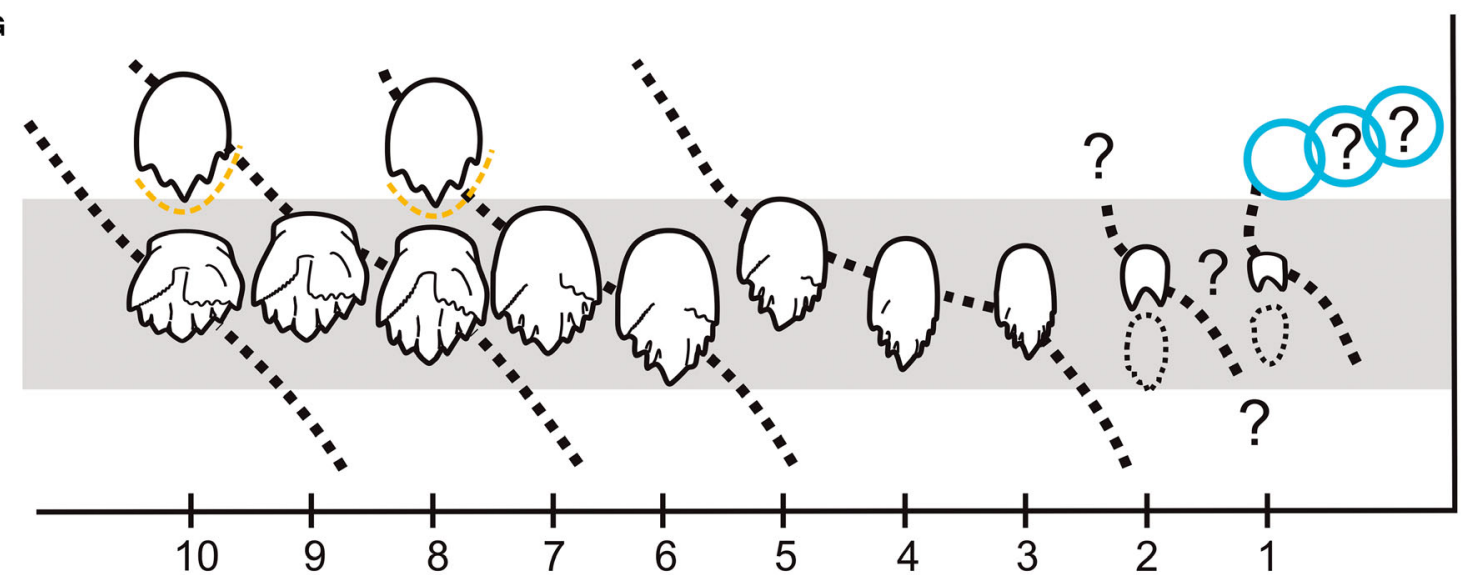


tooth positions and the left dentary has 10 , in both cases counting the absent D3 (Pol et al. 2011; Becerra et al. 2014; Fig. 4A-D). An additional unerupted 11th tooth in the left toothrow and several replacement teeth at different stages of development in both dentaries can be $3 \mathrm{D}$ reconstructed with the available $\mu \mathrm{CT}$ information (Fig. 4A-D). The tooth at the left D11 position has separated from its root and is slightly displaced posteroventrally towards the base of the coronoid process (Fig. 4C, D), but because it is below the alveolar level and lacks an open alveolus, we interpret this tooth as unerupted. This unerupted D11 tooth strongly suggests the incorporation of tooth positions posteriorly during the ontogeny of the species, as documented for Heterodontosaurus (Butler et al. 2008a) and other ornithischians (Hübner \& Rauhut 2010).

Two lines of evidence support active tooth replacement in the dentaries of MPEF-PV 3211: differential wear along the toothrow (Table 1), and the $3 \mathrm{D}$ reconstructed replacement teeth. The teeth at positions D9-D11 in the right dentary are differentially worn in a pattern expected in fore-aft-directed replacement waves (Fig. 5A-F). The presence of crenulated cutting edges in denticles, an autapomorphy of Manidens only observed in the right D9 tooth position of MPEF-PV 3211 (Pol et al. 2011), provides evidence that this is a freshly erupted crown (Fig. 5E, F). SEM of the right D10-D11 tooth positions allows us to identify extensive wear on most of the labial face of the D10 (apical and basal wear components contacting each other), and less extensive wear with separate apical and basal components in D11 (Table 1, Fig. 5AD). Together with the left positions of D4-D5 (which show a posteriorly growing wear development, as in MPEF-PV 3809; Fig. 5G-J), the final positions in the right dentary are the only postcaniniform crowns with confirmed wear facets in MPEF-PV 3211 (Fig. 5A-J). The differential development of wear in the posterior dentition (D9 lacks wear, D10 is extensively worn, and D11 shows barely developed wear) marks the last functional tooth of a replacement series (youngest functional tooth) and the beginning of another (extensively worn tooth followed by a barely worn tooth). Similar interpretations of different times of eruption between functional teeth were made for Lanasaurus, Lycorhinus, and Heterodontosaurus, with more worn crowns presumed to be older (Gow 1975, 1990; Hopson 1980; Norman et al. 2011; Sereno 2012). The tooth at the left D9 position, although slightly displaced, corresponds to a still erupting crown at the time of death (Figs 4C, D, 5L). This young tooth is the last of its replacement wave, signalling the beginning of another series, and slightly interrupting the continuity of the cutting margin of the toothrow (Fig. 5L). Unerupted replacement teeth associated to root resorption are identified at positions D6, D7 and D8 for the left dentary; and at D7, D8 and D10 for the right one (Figs 4A-D, 5K, L). Early stages of replacement teeth without associated root resorption are identified in positions D2, D4 and D9 for the left dentary; and D4, D5 and D9 in the right dentary (Figs 4, 5K-L). The difference in number of functional teeth (with an unerupted D11 in the left dentary but erupted in the right dentary) and the variable ordering of different stages of replacement teeth between dentaries (including the enlarged caniniforms and the cheek dentitions) indicate an asynchronous tooth replacement between the left and right dentary dentitions. In fact, for each dentary tooth position we can observe a more advanced stage of tooth development between the left and right cheek teeth, characterizing an offset between replacement waves acting on the jaws (Fig. 5K, L). For instance, the right D6 position has a complete tooth with no signs of root resorption and lacks a replacement tooth, but the left D6 tooth features advanced resorption on its root and a well-formed replacement crown (Fig. 4). Similarly, the right D9 is newly erupted (lacks wear) and fully functional with a replacement tooth germ in formation, but the left D9 is a still erupting tooth with an associated replacement tooth germ as well (Fig. 4). If considering a wave replacement pattern, the functional right D6 corresponds to the unerupted tooth at the left D6 (and the functional left D6 to an already replaced right D6), the functional right D9 corresponds to the erupting left D9, and the functional right D11 to the unerupted D11 in the left one (Fig. 5K, L). Considering these differences in stages between dentitions, the right dentary seems to be a step ahead of the left one. The arrangement of functional teeth of each replacement series follows a succession of

FIG. 4. Manidens condorensis specimen MPEF-PV 3211, 3D reconstructions of the dentary dentition and successive sagittal $\mu \mathrm{CT}$ sections of the dentary. A-B, right dentary dentition in: A, lateral; B, medial view. C-D, left dentary dentition in: C, lateral; D, medial view. E-F, sagittal (E) and horizontal (F) $\mu \mathrm{CT}$ sections at the anterior dentition region around the left D3 tooth position. G-H, coronal $(\mathrm{G})$ and sagittal $(\mathrm{H})$ sections at the left D6 tooth position detailing the replacement tooth D1 and its tooth crypt. A-D, functional teeth in orange, replacement teeth in yellow, tooth replacement for the enlarged caniniform in blue (its tooth crypt in lighter blue), unerupted left D11 tooth position in green, dotted lines indicate the alveolar level. Abbreviations: D1, enlarged caniniform positioned as the first dentary tooth position; D2-D11, second to 11th functional tooth positions; rD1, tooth replacement for the enlarged caniniform; rD2, rD4-rD10, replacement teeth of tooth positions D2 and D4 to D10; tcrD1, tooth crypt of the replacement for the D1 position. Scale bars represent: $5 \mathrm{~mm}(\mathrm{~A}-\mathrm{D}, \mathrm{G}, \mathrm{H}) ; 2.5 \mathrm{~mm}(\mathrm{E}, \mathrm{F})$. 

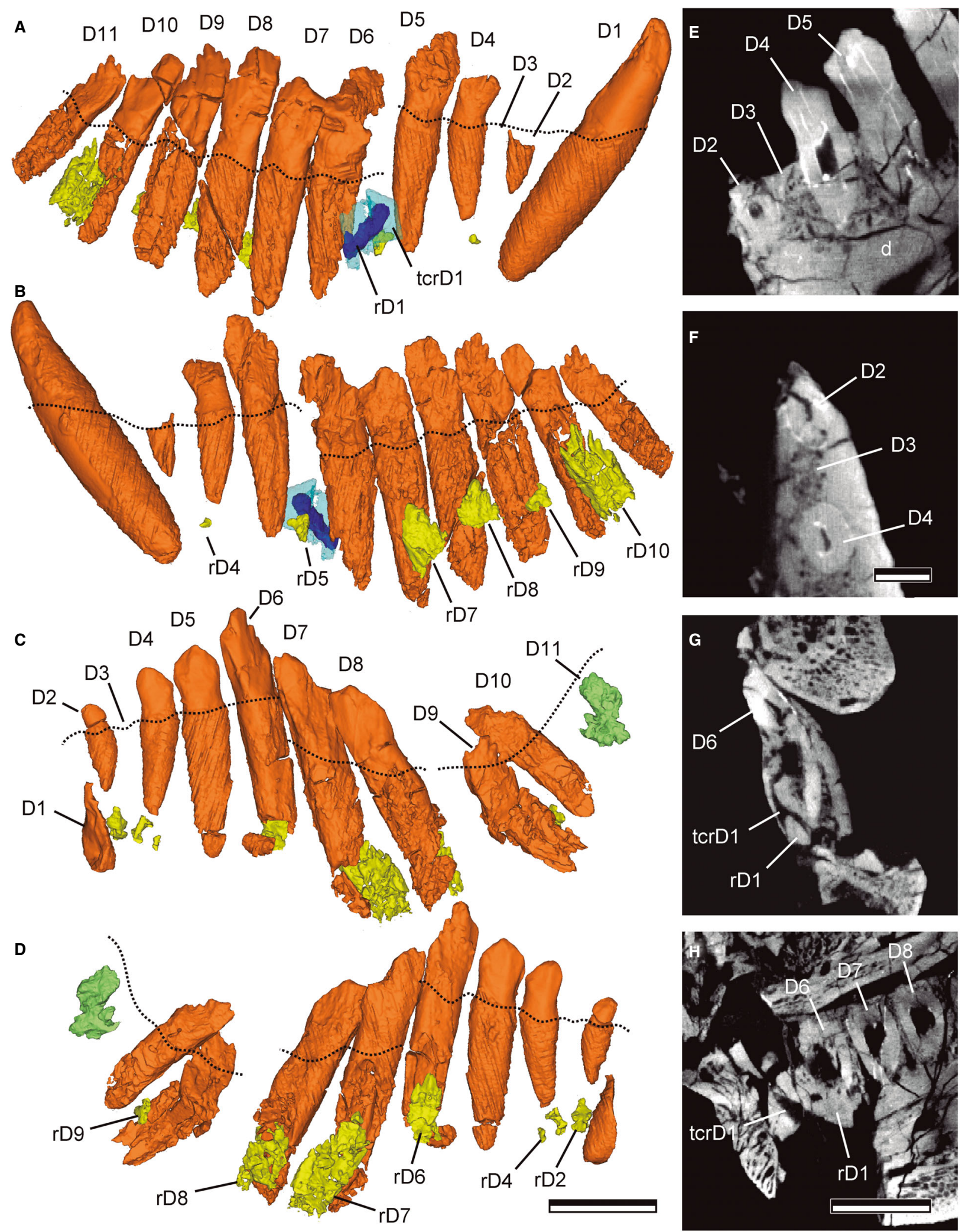

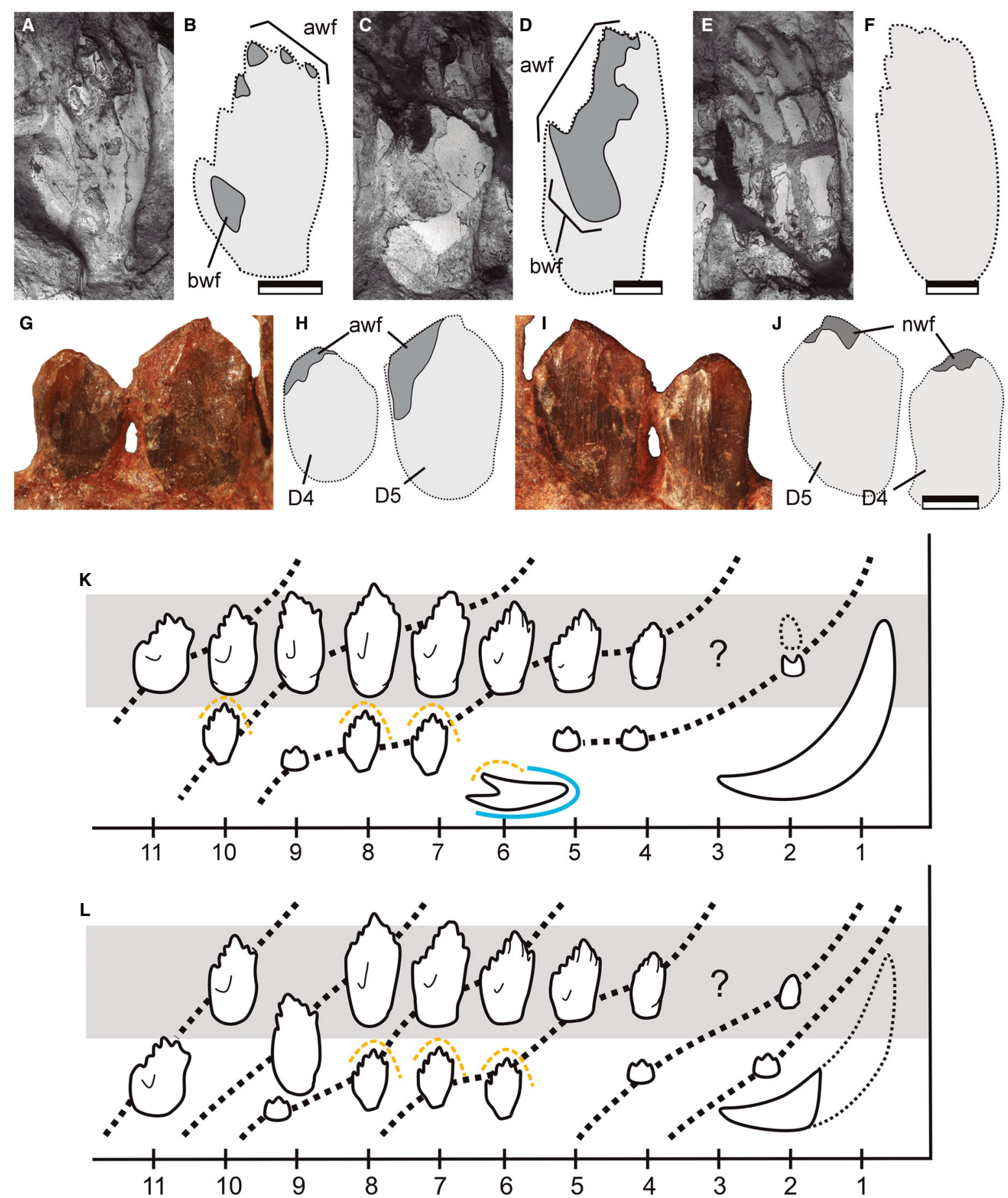

FIG. 5. Manidens condorensis specimen MPEF-PV 3211, worn dentary teeth and hypothetical replacement series acting in the dentary tooth rows. $\mathrm{A}-\mathrm{B}$, tooth position right $\mathrm{D} 11 . \mathrm{C}-\mathrm{D}$, tooth position right $\mathrm{D} 10$. E-F, tooth position right D9. G-J, tooth positions left D4D5. A, C, E, SEM. G, I, photographs. B, D, F, H, J, drawings. A-F, G-H, teeth in labial view. I-J, teeth in lingual view, evidencing the presence of wear facets in the non-functional (lingual) face of the crowns. K-L, right (K) and left (L) dentitions with hypothetical replacement series (thick dotted lines, tooth position along the horizontal axis, functional teeth in the grey area), anterior to the right, the missing right D2 and the half of the left caniniform are drawn with thin dotted lines, caniniform tooth crypt is in blue, the segmented yellow lines indicate root resorption, early and latter tooth germs are drawn with different sizes and shapes. Abbreviations: ?, missing D3; awf, apical wear facet; bwf, basal wear facet; D4-D5, functional tooth positions D4-D5; nwf, wear facet developed at the non-functional face of the crowns. Scale bars represent $1 \mathrm{~mm}(\mathrm{~A}-\mathrm{B}, \mathrm{C}-\mathrm{D}, \mathrm{E}-\mathrm{F}, \mathrm{G}-\mathrm{J})$. 
$1-?-3-3-2$ in the right dentary, and of $1-?-2-2-2-1$ in the left dentary, with the left D9 tooth as a still emerging tooth (Fig. 5K-L). In both dentaries, the absence of a tooth in the D3 position hampers the inference of a replacement pattern for the anterior dentition and its relationship with the rest of the toothrow, because it could be part of the preceding or the succeeding replacement series in both dentaries (Fig. 5K, L). Each replacement series includes up to six teeth in different degrees of development in the right dentary, and up to four in the left dentary (considering the tooth germs, Fig. 5K, L). In addition, it is highly likely that the replacement of the enlarged caniniform responds to a different process than that of the cheek dentition. Due to its large size, the times of development (if the replacement rate is similar to that for the cheek teeth) or the replacement rate (if the times of development are the same for the entire dentition) of this caniniform surely differ to that of the cheek dentition. In this case, a differentially slower replacement rate for the enlarged caniniforms, with similar times of tooth development to the cheek dentition that allows the saving of energy and resources (permitting the appearance of polished apical facets due to tooth-food interaction; Becerra et al. 2014), seems more likely than a differentially faster caniniform development to achieve a similar replacement rate than cheek teeth, which involves higher energy expenditure.

Specimen MPEF-PV 3808. The autapomorphies of the species Manidens condorensis present in this specimen were identified mostly in the casts of the damaged teeth. This specimen preserves a buried enlarged caniniform in the D1 position and the typical asymmetric diamondshaped teeth of Manidens condorensis. The apex of the tooth at the D7 position and the negative casts in the rock of many other denticles bear crenulated edges, and the sediment between teeth contains the cast of a mesial cavity in the tooth positions D5-D7 that is absent in the anterior positions (Fig. 6D-J). Fortunately, the preservation of the tooth positions D2-D7 provides new anatomical information about the first postcaniniform teeth, poorly preserved in MPEF-PV 3211. Posterior to the preserved toothrow, the midposterior cheek dentition is not preserved but six empty alveoli suggest up to 13 teeth for the right dentary, with the last two located over the base of the coronoid process (Fig. 6D). An isolated dentary tooth lies near the dentary, which might correspond to the same specimen. The cast of the enlarged caniniform D1 exposes only its crown base but can be completely 3D reconstructed as a curved and long element (Fig. 6C, F). The postcaniniform diastema identified in MPEF-PV 3211 is present in MPEF-PV 3808 (Fig. 6D-F). Posterior to this diastema, the low and subconical D2 position is preserved as a cast, being slightly compressed labiolingually and anteriorly inclined, with the base bulging above its root, its apex in the middle of the crown axis, and lacking carinae and serrations, information not preserved in MPEF-PV 3211. The following D3 tooth (absent in MPEF-PV 3211), is slender and apicobasally high, with a rounded profile on its mesial carina and a distal carina with a sharp edge, lacking denticles or serrations. The crown is slightly compressed lateromedially, basally bulbous, mesially flat in its portion facing the D2 tooth, and with a convex mesial and concave distal profile in lateral view characterizing a posterior curvature (Fig. 6DF). The anatomy of this crown is completely different to all other known teeth for the species, resembling a reduced and slender caniniform as tall as the following tooth (D4) but slenderer. A low and conical tooth followed by a reduced caniniform as the first cheek tooth in the dentary dentition is similar to the condition of Abrictosaurus among heterodontosaurids (NHMUK RU B54), but the D3 in MPEF-PV 3808 has a similar height to the following crown rather than being higher than its neighbouring teeth, as in Abrictosaurus (Sereno 2012). However, these small caniniforms are not homologous. Abrictosaurus lacks the enlarged caniniform, meaning that the reduced peg-like tooth and the following reduced caniniform correspond to the tooth positions D1-D2 in Abrictosaurus and to D2-D3 in Manidens (Thulborn 1974; Norman et al. 2011; Sereno 2012). A reduced caniniform as a component of the cheek dentition also resembles the first maxillary tooth of Echinodon (NHMUK 48210 and 48209; Galton 1978; Sereno 2012), but as in Abrictosaurus, this crown exceeds the apicobasal height of following teeth. Thus, the combination of characters at the D1-D3 tooth positions is unique to Manidens within Heterodontosauridae and Ornithischia, as represented by the specimen MPEF-PV 3808 but not the holotype MPEF-PV 3211 (see Discussion). The tooth at the D4 position and successive teeth show the typical asymmetric diamond-shaped morphology of postcaniniform dentary cheek teeth of Manidens (Pol et al. 2011; Becerra et al. 2014), although these features are less prominent for D4 (a larger apex and denticles proportionally smaller than in other dentary teeth). The remaining D5-D7 are as described by Pol et al. (2011) and Becerra et al. (2014) for dentary teeth (Fig. 6).

Regardless of being poorly preserved, MPEF-PV 3808 shows aspects of tooth replacement not identified in other specimens (Fig. 6E, F). The apex and base of the crown at the D6 position are below the level of those in D5 and D7, with its base below the alveolar margin. The tooth at the D6 position was erupting at the time of death, signalling the last functional tooth of a replacement series (as the youngest tooth emerging) and the beginning of the next. However, the lack of information on other replacement teeth leaves open the possibility that all teeth 


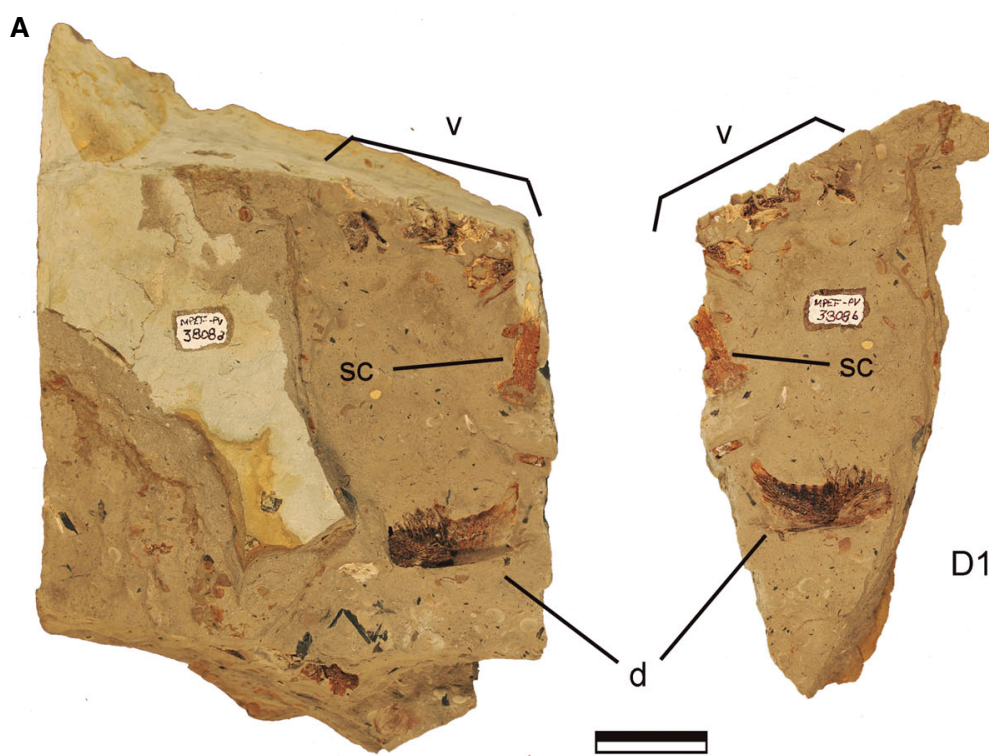

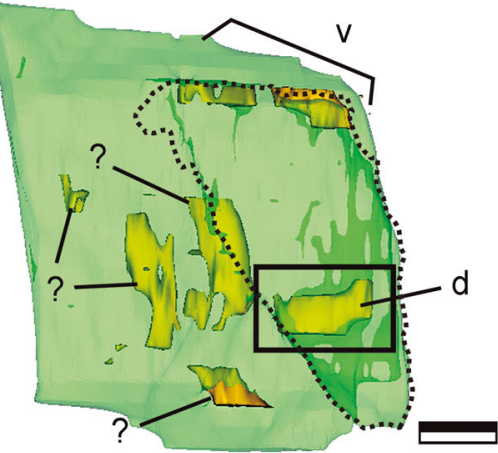

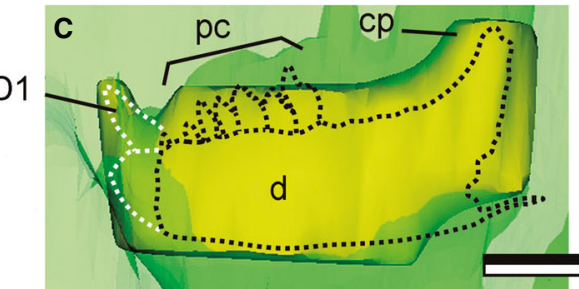

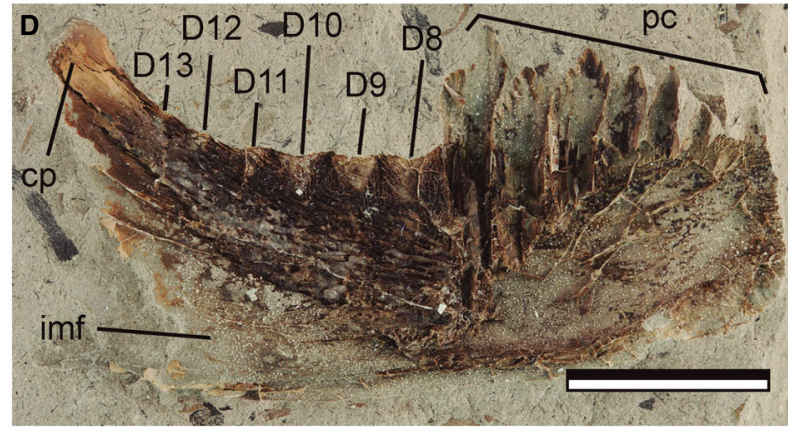
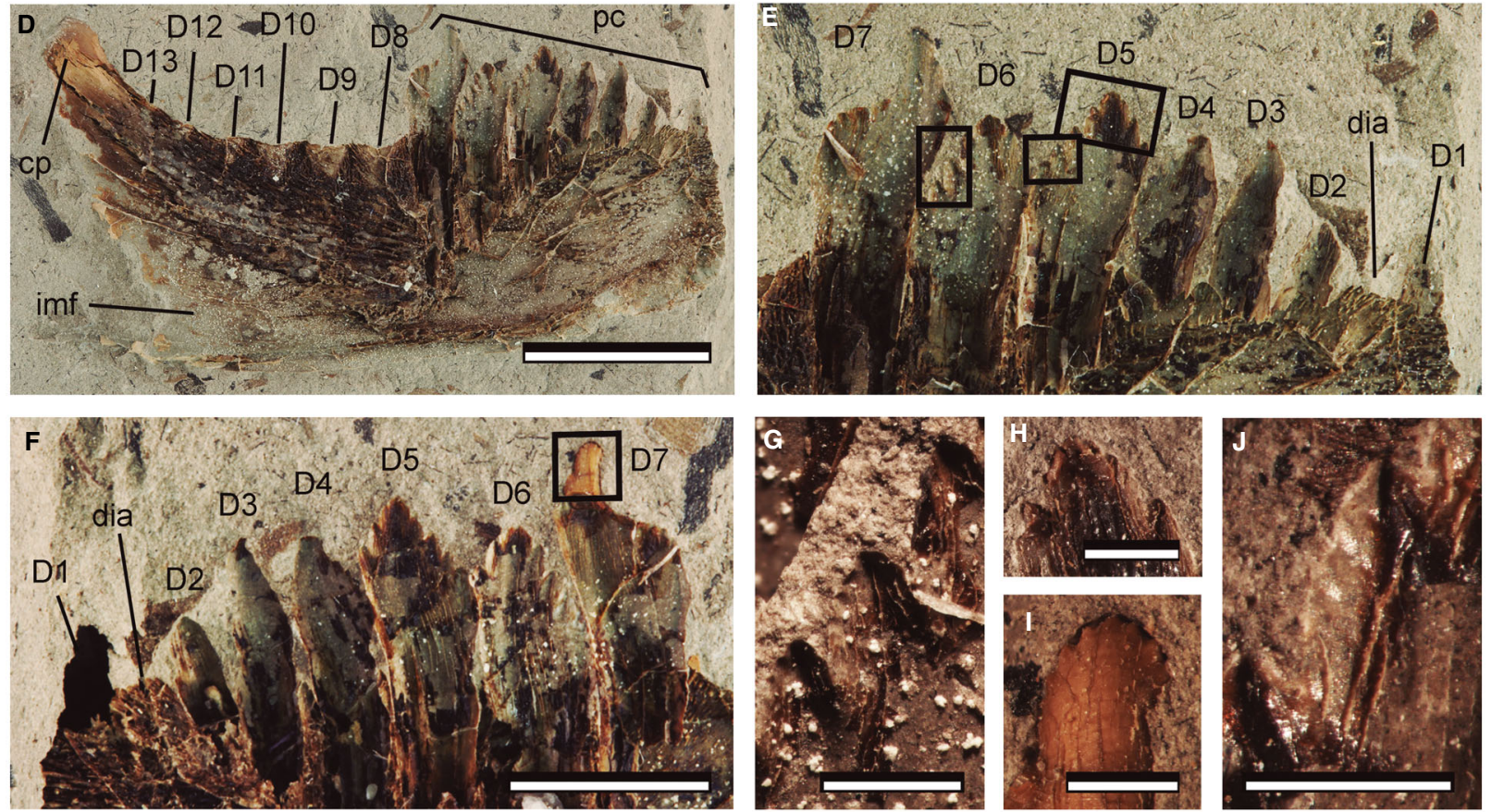

K
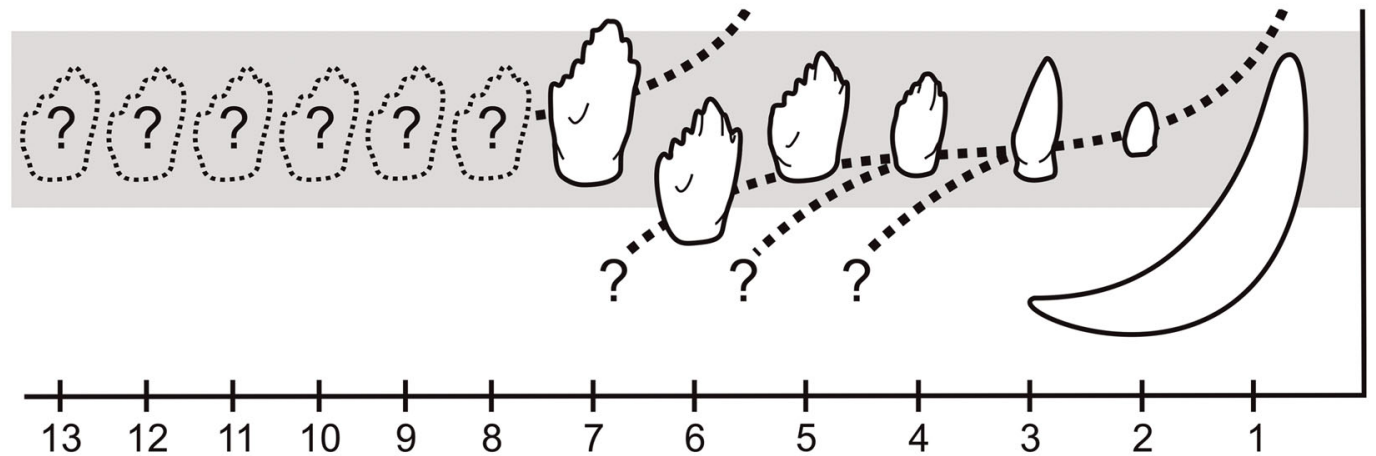
FIG. 6. Manidens condorensis specimen MPEF-PV 3808, fossil remains and dentary dentition. A, general view of the specimen in the matrix (both faces). B, low-resolution 3D reconstruction of all fossil remains; the elements exposed in A (dotted outline in B) are identifiable, but those inside the rock are unknown, and the scapula visible in A is not resolved due to the low detail. C, close up of the right dentary $3 \mathrm{D}$ reconstruction at low resolution with an outline of its shape as seen in $\mathrm{D}$ (including a reconstruction of the D1). D-F, details of the preserved dentition. G-J, close-up of the crenulated margins of denticles, autapomorphic of Manidens. K, hypothetical replacement series (thick dotted lines) acting in the dentition (tooth positions along the horizontal axis, functional teeth in the grey area); anterior to the right; the missing D8-D13 are shown with thin dotted lines; the ordering of the replacement series is unknown (?). Abbreviations: ?, unknown fossil remains; alv, empty alveoli filled with sediment; cp, coronoid process of the dentary; d, dentary; D1-D13, functional tooth positions in order from the enlarged caniniform to the 13th tooth; dia, postcaniniform diastema; imf, internal mandibular fossa; pc, preserved postcaniniform dentition; sc, scapula; v, vertebrae. Scale bars represent: $3 \mathrm{~cm}$ (A, B); $1 \mathrm{~cm}(\mathrm{C}, \mathrm{D}) ; 5 \mathrm{~mm}$ (E, F, same scale bar); $1 \mathrm{~mm}(\mathrm{G}-\mathrm{J})$.

anterior to D6 pertain to the same replacement wave or comprise the functional teeth of more than one series (Fig. 6K). This emerging D6 exposes its mesial (but not distal) denticles to shearing, implying a minor interruption of the continuity of the slicing margin between the tip of the D6 and the mesial margin of the D7. A wider interruption of the slicing margin of the toothrow may take place during the early stages of tooth replacement (as in the left D9 of MPEF-PV 3211), but the duration of this interruption may vary. In addition, although the tooth at the D6 position is still emerging, it already contains in its mesial cavity the distal region of the D5 tooth, and in turn it is distally included in the mesial cavity of tooth D7. It is highly important to note that the interlocking of neighbouring teeth in the preserved toothrow is maintained during the eruption of D6 regardless of whether it belongs to a different replacement wave than the adjacent functional teeth. The early stages of replacement develop medial to the tooth to be replaced in all reptiles (Edmund 1960), including Manidens. Possibly, the later stages of replacement prior to tooth eruption in the cheek dentition were in an apicobasal direction (which explains the interlocking of teeth during eruption), instead of both apicobasally and mediolaterally. This change in the direction of replacement allows maintenance of the close-packing of teeth while these are replaced, a process possibly occurring in the entire midposterior cheek dentition. The functional integration of a still emerging tooth without affecting the interlocking of the toothrow ensures the optimal functioning of the
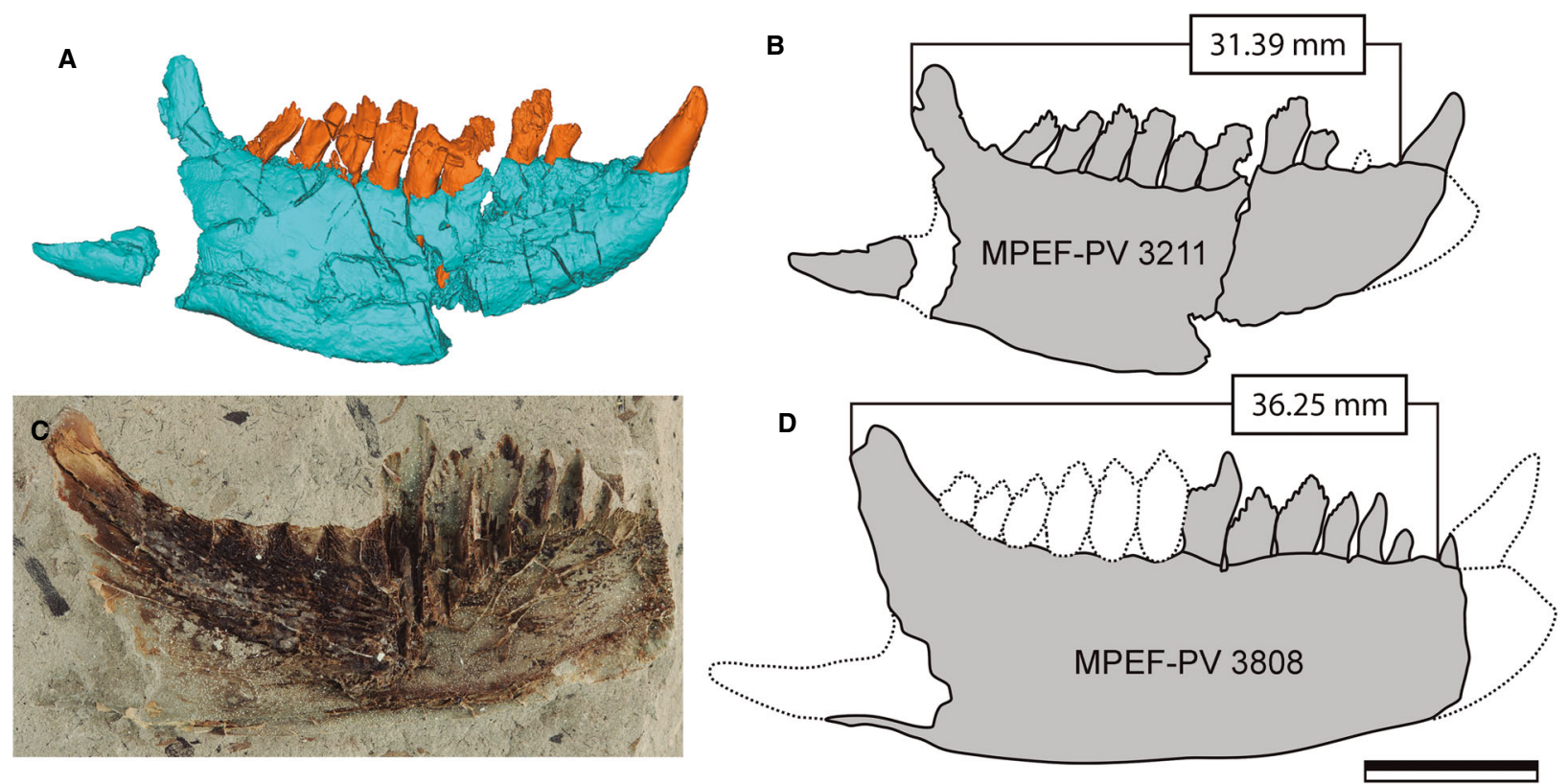

FIG. 7. Manidens condorensis, size comparison between dentaries of specimens MPEF-PV 3211 (A-B) and MPEF-PV 3808 (C-D). $\mathrm{A}, 3 \mathrm{D}$ reconstruction of the left dentary in medial view of MPEF-PV 3211 positioned to achieve a continuous view of the alveolar margin, disregarding the crack at the D5-D6 tooth positions. C, dentary of MPEF-PV 3808 as exposed in the rock. B, D, line drawings showing the measured lengths of the dentaries. Scale bar represents $1 \mathrm{~cm}$. 

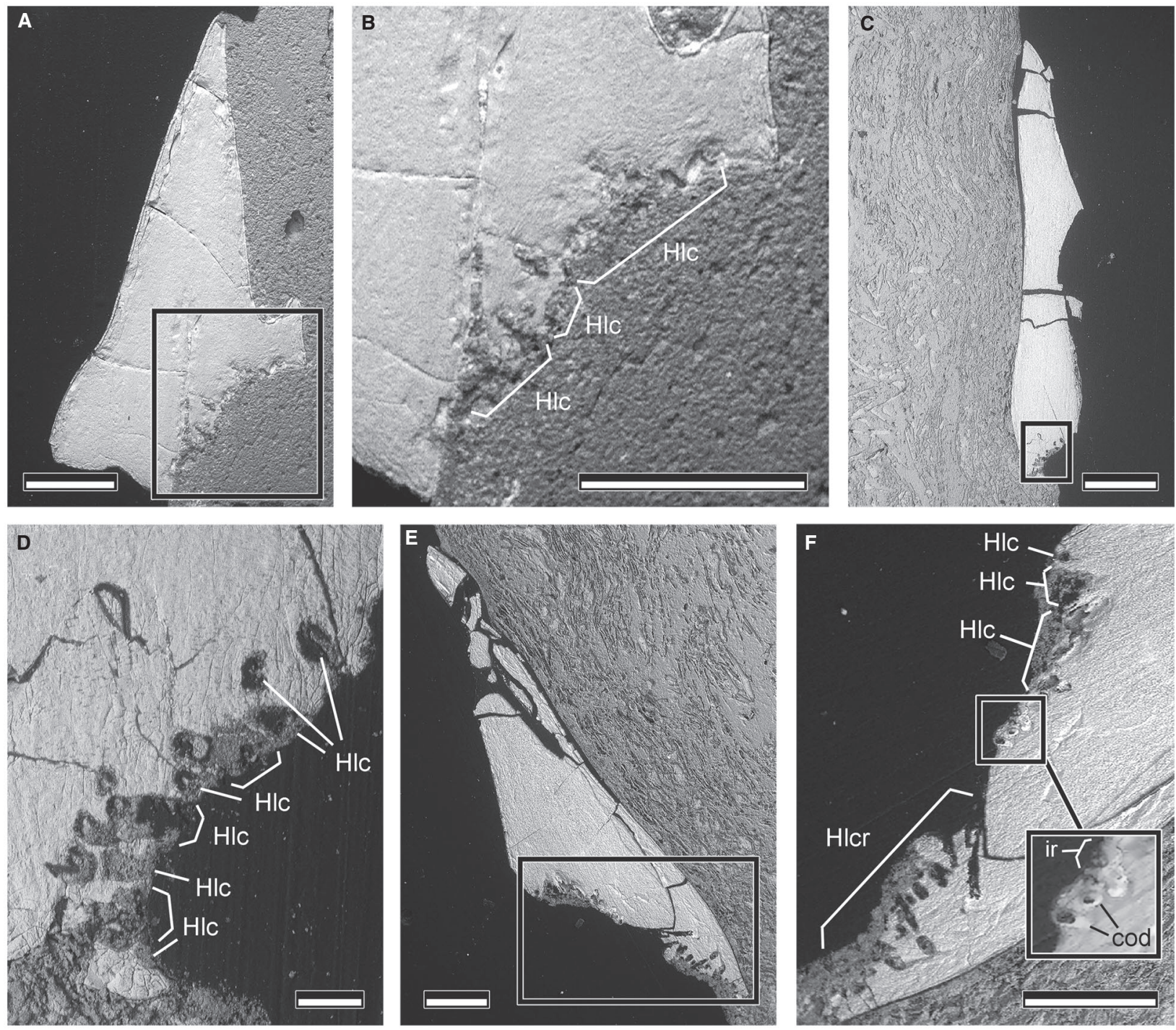

FIG. 8. Manidens condorensis, SEM of longitudinal sections from isolated teeth referred to the species (modified from Becerra \& Pol 2020). A-B, maxillary tooth MPEF-PV 10823. C-F, dentary tooth MPEF-PV 10862: C-D, MPEF-PV 10862b; E-F, MPEF-PV 10862a. Abbreviations: cod, 'cast' of odontoclast; Hlc, Howship's lacuna/lacunae; Hlcr, region with Howship's lacunae; ir, irregular region. Scale bars represent: $500 \mu \mathrm{m}(\mathrm{A}, \mathrm{B}, \mathrm{E}, \mathrm{F}) ; 1 \mathrm{~mm}(\mathrm{C}) ; 100 \mu \mathrm{m}(\mathrm{D})$.

dentition, reduces the possibility of interdental malocclusion and increases the effectiveness of the jaw function, derived features related to an herbivorous dentition but present in a species with primitive craniomandibular morphology and function (Becerra \& Pol 2020).

The difference in tooth count between the specimens MPEF-PV 3211 and 3808 is possibly due to their size difference (Fig. 7). The line parallel to the dentary axis from the posterior end of the alveolus of D1 to the posterior end of the coronoid process measures $36.25 \mathrm{~mm}$ in MPEF-PV 3808 and $31.39 \mathrm{~mm}$ in MPEF-PV 3211, possibly representing different ontogenetic stages (Fig. 7). Increasing tooth count related to ontogeny occurs in
Heterodontosaurus (Butler et al. 2008a; Norman et al. 2011; Porro et al. 2011), with 7 teeth in the incomplete maxillary toothrow of a juvenile specimen (SAM-PKK10487), 11-12 maxillary teeth and 11 dentary teeth in a larger specimen (SAM-PK-K1332), and 12 dentary teeth in an even larger one (NM QR 1788). Similar cases have also been documented in Ornithischia (Sereno 1991; Hübner \& Rauhut 2010). The posteriormost teeth in both dentaries of MPEF-PV 3211 are located near the base of the coronoid process, whereas in MPEF-PV 3808 two tooth positions emerge at the dorsal margin of the same region, forming a toothrow slightly curved posteriorly and supporting the increased tooth count by the addition 
of new teeth on the posterior end of the toothrow. Other heterodontosaurids including Heterodontosaurus (SAMPK-K1332), Echinodon (NHMUK 48215a and 48215b), Lycorhinus (SAM-PK-K 3606) and Abrictosaurus (NHMUK RU B54) also have the posteriormost teeth over the base of the coronoid process and a slight concave profile of the toothrow in lateral view.

\section{Isolated maxillary and dentary teeth}

The exploratory sectioning of isolated teeth referred to Manidens condorensis revealed new features associated with root resorption (Fig. 8). The activity of odontoclasts in the resorption region is evident in the longitudinal section of a dentary tooth (MPEF-PV 10862a and b, Fig. $8 \mathrm{C}-\mathrm{F}$ ) but is less pronounced in the same section of a maxillary tooth (MPEF-PV 10823, Fig. 8A, B). In MPEF-PV 10862, a single concavity is identified as the area of action of odontoclasts, reaching slightly further than the level of the enamel layer externally, at the lingual face of the crown (Fig. 8C-F). At the resorption region, several eroded cavities forming tunnels with subcircular ends, and in some cases contacting each other laterally (Fig. 8D, F), were identified as Howship's lacunae (40$45 \mu \mathrm{m}$ wide and up to $277.39 \mu \mathrm{m}$ deep). The ends of some of these resorption channels featured subspherical and hollow structures (Fig. 8F). Odontoclasts of living vertebrates include loose apatite crystals, released by dentine digestion, that remain in the attacking region enclosed by their ruffled border and within their endocytotic vacuoles (Sasaki et al. 1988; Teitelbaum 2000; Väänänen et al. 2000; Saltel et al. 2004). The preservation of the siliceous replacement of loose apatite crystals within the odontoclasts possibly shaped these subspherical structures, thus representing 'casts' of odontoclasts. In MPEF-PV 10862a, two 'casts' of odontoclasts are 33.4/ $41.3 \mu \mathrm{m}$ wide and $73.9 / 87.5 \mu \mathrm{m}$ long, respectively, similar in size to odontoclasts of extant reptiles (e.g. Liolaemus gravenhorsti, $51.8 \mu \mathrm{m}$ wide and $74.9 \mu \mathrm{m}$ long, measured from Fuenzalida et al. 1999). Nearby, a small irregular region is identified, c. $137.35 \mu \mathrm{m}$ long and $79.75 \mu \mathrm{m}$ wide, which is possibly the result of the activity of several odontoclasts, although no 'casts' were preserved. Specimen MPEF-PV 10823 shows a lingually placed attack front with signs of odontoclast activity (sectioned resorption tunnels and irregular external surface), and a more labially placed attack front with a smoother surface (Fig. 8A, B). In all cases, the enamel is not affected by the root resorption, and the root is principally attacked in its lingual region. The longitudinal sections indicate that tooth replacement produces an apicolabially oriented resorption process up to the level of the basal enamel boundary. Similar mechanisms of root resorption have been identified in other heterodontosaurids (Butler et al. 2012; Sereno 2012) and other ornithischians (Colbert 1981, figs 9-10; Horner et al. 2004; Dodson et al. 2004; Tanoue et al. 2009; Thomas 2015; Porro et al. 2015, fig. 3; LeBlanc et al. 2016). A high proportion of isolated teeth referred to Manidens preserve a hollow base, indicating that they have been replaced: out of 13 isolated dentary teeth referred to Manidens only two of them have preserved roots (MPEF-PV 3814 and 3816). Of the replaced teeth, some do not have signs of wear (i.e. preservation of marginal enamel crenulations on denticles, such as in MPEF-PV 3815), some teeth are incipiently worn that do not expose the dentine (e.g. MPEF-PV 1719 and 3811), some teeth have wear facets exposing worn enamel and dentine (e.g. MPEF-PV 1786, 3812 and 3813; see Becerra et al. 2014), and there is only one crown of an extensively worn isolated tooth (MPEF-PV 10866, Becerra et al. 2018, online resource 1). Similarly, three of the four isolated maxillary teeth are slightly worn but show evidence of tooth replacement (Becerra et al. 2018, online resource 1). Thus, a high proportion of isolated teeth of Manidens ( $82.3 \%$ of the total known teeth) have traces of root resorption and wear facets but were still functional (i.e. denticles have sharp cutting edges and are not completely worn). The replaced isolated teeth with different wear stages suggest that replacement timing in Manidens was independent of the wear processes. Although changes in the replacement rate during ontogeny cannot be inferred, differently developed wear in isolated teeth suggests continuous replacement for Manidens, in most cases occurring prior to the end of the functional life of the tooth.

\section{DISCUSSION}

\section{Intraspecific dimorphism in Manidens condorensis}

The dental formula in the dentary dentition of two specimens of Manidens condorensis is clearly different in the presence/absence of a small caniniform in the D3 position. The D3 positions in both dentaries of MPEF-PV 3211 have an alveolar socket but lack root fragments and are filled by spongy bone (Fig. 4E, F), implying that the space for a tooth exists. Considering the asynchronous arrangement of replacement waves between dentaries and the similar times of replacement for all the teeth in the cheek dentition, it is expected that at least one of the D3 positions would have a replacement tooth developing in MPEF-PV 3211. However, there are no replacement teeth at these positions in either of the dentaries. It is possible that palaeobiological coincidences led to the loss of the D3 position in both jaws of MPEF-PV 3211 but not in 3808. Three other explanations can be proposed, which 
are related to the size difference between MPEF-PV 3211 and MPEF-PV 3808: (1) the anterior dentition of Manidens was replaced at a different or slower rate than the midposterior dentition; (2) a tooth at the D3 position was completely absent in some individuals while in others it developed as a small caniniform; or (3) the small caniniform at the D3 position developed only when larger body sizes were reached. A differential replacement rate between the anterior and the midposterior dentition can occur if the replacement of the enlarged caniniform affected the formation of replacement teeth for the anterior region (which may occur under the zone of inhibition theory). In this case, the resorption process occurring at the right D6 position in MPEF-PV 3211, next to the D1 replacement, shows that the presence of this D1 caniniform tooth in development affects the functioning of the surrounding bone, and possibly the development of replacement teeth for the anterior dentition. Several replacement teeth were spotted in this dentary for tooth positions D2 and D4 but not for D3, which may contradict this idea. The other hypotheses, however, imply the consideration of intraspecific dimorphism, which was possibly related to sexual dimorphism (i.e. only one of the sexes developed the small tusks) or sexual maturity (i.e. one or both sexes developed the reduced tusks but in later stages of ontogeny). The presence of supernumerary teeth in a diastema recalls the caniniform (albeit derived from the premolar series) 'wolf teeth' occasionally observed in modern horses (Hole 2015). Size-correlated and/or age-correlated addition of tooth positions is well documented in both mammalian (Miles 1963; Grant 1982) and reptilian (Westergaard \& Ferguson $1987,1990)$ ontogeny. Is important to note that all possibilities are equally likely, whereas two of the three explanations include the intraspecific (sexual or ontogenetic) dimorphism.

Intraspecific dimorphism within Heterodontosauridae is not a novel idea (Sereno 2012). There are unresolved discussions related to the absence of enlarged caniniforms such as the last premaxillary and the first dentary teeth in Abrictosaurus (NHMUK RU B54) as evidence of sexual dimorphism, with this specimen being a female of its own species or female for Heterodontosaurus (Thulborn 1974; Hopson 1975; Norman et al. 2011; Sereno 2012). Contrary to Abrictosaurus in Heterodontosauridae and Diictodon among synapsids (Sullivan et al. 2003), the existence of the enlarged dentary caniniform D1 as a dimorphic feature in Manidens cannot be discussed because it is recognized in both MPEF-PV 3211 and 3808 (Figs 4, 6). However, differences in shape or proportional size in the caniniform between 3211 and 3808, such as the size contrast of canines occurring between sexes of primates and camelids (Leutenegger \& Kelly 1977; Harvey et al. 1978; Plavcan 2001; Plavcan \& van Schaik 1993), cannot be confirmed with the available data. In contrast, ontogenetic or sex-related differences in the dental formula within the same species, such as that possibly represented by MPEF-PV 3211 and MPEF-PV 3808 for Manidens, occur in several lineages of mammals (McPherson \& Chenoweth 2012). For instance, although the phylogenetic history of horses demonstrates the presence of canines in both sexes (Gingerich 1981; Vollmerhaus et al. 2003), in extant species only male horses develop this tooth position, commonly used to assist in male-male combat and defensive behaviour (Bennett \& Hoffmann 1999). In a similar way, the differences between MPEF-PV 3211 and 3808 regarding the presence/absence of the small caniniform D3, if representing intraspecific variation in dental formula related to sex or ontogeny, might possibly represent a response to sexual selection pressure. The small caniniform at the D3 position possibly assisted the enlarged dentary caniniform (and the hypothetical premaxillary dentition) in male-male combat or defensive behaviour (as frequently assumed for other heterodontosaurids; Thulborn 1974; Hopson 1975; Molnar 1977; Butler et al. 2008a; Norman et al. 2011; Sereno 2012). Under this hypothesis, the enlarged dentary caniniform could be functionally similar to the fighting teeth of South American camelids, being present in one (if related to sexual dimorphism) or both sexes (if related to ontogeny) for defence and intraspecific combat. In addition, intraspecific dimorphism between sexes is identified in the craniomandibular apparatus and dentition of several extant species of Squamata (Shine 1989; Camilleri \& Shine 1990). In Squamata, the dimorphic features affect the number and size of teeth (Edmund 1969; Thorpe 1989; Greer 1991), but also the craniomandibular proportions and jaw articulation (Anderson \& Vitt 1990; Shine 1991; Herrel et al. 1995), being frequently related to intraspecific niche divergence between sexes (Shine 1989; also occurring in birds; Temeles et al. 2000, 2010). For Manidens, it is possible that the presence of this D3 caniniform tooth in later stages or in different sexes is related to dietary intraspecific differences, making it possible to access a different food resource and enabling at least a slight niche divergence between sexes or ontogenetic stages. As in Heterodontosaurus (Butler et al. 2008a), Manidens features an isolated cheek tooth (MPEF-PV 10823) that is smaller in size than all other isolated teeth including those from MPEF-PV 3211 (Becerra \& Pol 2020), indirectly implying that tooth replacement in Manidens allowed increasing tooth size (MGB pers. obs.). The size difference between the smaller MPEF-PV 3211 (lacking the D3 position) and the larger MPEF-PV 3808 (with the D3 position), and the structural differences in enamel between an isolated cheek tooth from a smaller individual (thinner and simpler enamel) and other sectioned larger crowns (thicker and more 
complex enamel) support the possibility of a changing diet during the ontogeny of Manidens (Becerra \& Pol 2020), as occurs in several reptiles (Berkovitz \& Shellis 2016).

Proposed behavioural differences due to sexual dimorphism, or varying diets due to sex or ontogeny are weakly supported by differences in the dental formula, but these ideas could be strengthened if body size difference between MPEF-PV 3808 and MPEF-PV 3211 was linked to sex. Additionally, a better understanding of this possible intraspecific variation in Manidens could be achieved if MPEF-PV 3808 had two dentaries showing a reduced D3 caniniform (such as the absence of D3 in MPEF-PV 3211), and if the premaxillary dentition was known for the two specimens. Future new specimens will allow a better understanding of the palaeobiology of Manidens, including this possible intraspecific dimorphism.

\section{Tooth replacement in Manidens condorensis}

Two contrasting hypotheses were first presented for tooth replacement in Heterodontosauridae: Charig \& Crompton (1974) proposed the lack of tooth replacement in Heterodontosaurus, while Gow (1975) and Hopson (1975) supported tooth replacement in the species. Gow (1975) inferred a wave-like replacement pattern based on differential wear facets in Lanasaurus (BP/1/4244), in which younger teeth were added posteriorly for each set of teeth (i.e. functional teeth of each replacement wave). This pattern of tooth replacement, involving a Z-spacing of 3.0, led the author to infer an external direction of the replacement wave from back to front (Gow 1975). A similar suggestion was made for Lesothosaurus (Thulborn 1971). Thulborn (1971) also considered limited replacement cycles and a similar style of tooth replacement for the rest of the heterodontosaurids. Hopson (1975), examining differential wear and tooth lifespan, reached similar conclusions for replacement of the dentary dentition of Lycorhinus SAM-PK-K3606 (fourth and seventh postcaniniform teeth being more extensively worn than the following teeth at the same series). The author inferred three replacement series (Zahnreihen) occurring in SAMPK-K3606, a probable continuous dental replacement for immature individuals (as in Lanasaurus; Gow 1975), and an active tooth replacement in more advanced ages than those represented by the size of SAM-PK-K1332 in Heterodontosaurus (Charig \& Crompton 1974). These hypotheses of dental replacement in Lanasaurus and Lycorhinus (Gow 1975; Hopson 1975) as a succession of replacement series in waves directed posteriorly, are similar to that inferred here for Manidens.

Thulborn (1978), when proposing wear development in the cheek teeth of Heterodontosaurus as a single, continuous facet along the entire tooth row and fore-aft food-grinding jaw movements, rejected the hypotheses of dental replacement presented by Hopson (1975) and Gow (1975). Instead, Thulborn proposed aestivation periods with a complete and rapid replacement of the cheek dentition rather than a wave-like pattern of anterior-to-posterior replacement and a cessation of replacement at maturity. The author linked the aestivation hypothesis to fore-aft food-grinding behaviour, thus avoiding the problematic gaps in the toothrow and preserving the entire grinding surface. Additionally, Thulborn (1978) justified the absence of isolated heterodontosaurid teeth at the Red Beds Formation according to the aestivation hypothesis, because these were all completely lost at specifically selected places rather than in a scattered manner. The author inferred a similar grinding behaviour and aestivation periods with fast tooth replacement for Lycorhinus (SAM-PK-K3606) but not for Lanasaurus (BP/1/4244), in which more loosely developed wear facets were attributed to an orthal food-chopping jaw mechanism with a modified wave-replacement pattern, more similar to Lesothosaurus than to heterodontosaurids. The aestivation hypothesis was rejected by Hopson (1980), who recognized differential tooth wear in the dentitions of Heterodontosaurus, Lycorhinus and Lanasaurus, and inferred an orthal jaw motion with a possible lateral-medial component, a continuous wave-like replacement with recognized replacement series, a Z-spacing of 3.0 and a cessation of replacement in mature individuals. Recently, new evidence of tooth replacement was identified in most heterodontosaurids, with erupting teeth seen in Echinodon (Sereno 2012, figs 13, 14, 18), Tianyulong (Sereno 2012, figs 22, 23), the heterodontosaurid material from the Kayenta Formation (Sereno 2012, fig. 9b), Abrictosaurus (Sereno 2012, fig. 33), Pegomastax (Sereno 2012, fig. 86) and Fruitadens (Butler et al. 2010, 2012, figs 2-7; Sereno 2012, figs 41, 45-52). Similarly, Sciscio et al. (2017) inferred continuous, low rate and asynchronous replacement in mature specimens of Lesothosaurus diagnosticus (BP/1/7853 and SAM PK K00426), although the pattern remains unclear (contrary to Thulborn 1978). Although unambiguous evidence of dental replacement organized in waves was confirmed in specimen SAM-PK-K1334 of Heterodontosaurus, indirect evidence for replacement (differential wear in teeth of SAM-PK-K337 and SAM-PKK1332; smaller teeth in the juvenile specimen SAM-PKK10487) has also been described (Hopson 1975, 1980; Butler et al. 2008a; Norman et al. 2011; Sereno 2012). Most authors agree on dental replacement in Heterodontosaurus with a possible cessation of tooth replacement in mature individuals (Hopson 1975, 1980; Norman et al. 2011; Sereno 2012), whereas its episodic (Norman et al. 2011) or continuous (Sereno 2012) replacement is still discussed. Butler et al. (2010) mentions active 
replacement in Fruitadens but with unclear pattern, although later work (Butler et al. 2012, fig. 4) shows a possible wave-like pattern. Although the functional dentition is broken in most specimens of Fruitadens, the dentary of the holotype LACM 115747 shows a D6 that might be newly erupted, a D7 that is slightly older (with its root visible below the crown), a D8 with a small replacing crown in formation, and a D9 with a large replacing crown developed (JAW, pers. obs.), thus potentially representing an additional species in Heterodontosauridae that might feature a wave-like replacement pattern.

Thus, although evidence of tooth replacement exists in Heterodontosauridae, the type (alternate or wave-like) and timing (continuous, episodic, cessation during maturity) of replacement seems to depend on the species and specimen, and it is possible that there is no single model for replacement in this clade. However, most authors describing tooth replacement in heterodontosaurids discard the aestivation hypothesis (Hopson 1980; Butler et al. 2008a, 2012; Norman et al. 2011; Porro et al. 2011; Sereno 2012). This study describes several lines of evidence of active, continuous and asynchronous replacement in Manidens condorensis, including both indirect (root resorption, differential wear, labiolingual offset of functional teeth pertaining to different replacement series) and direct (tooth crypts and replacement teeth) evidence from isolated teeth and specimens with complete dentition. In Manidens, replacement teeth develop in tooth crypts lingually and basally from the functional tooth row. During their development, these migrate first in an apical and lingual direction (forming a resorption pit lingually in the root of the tooth to be replaced), and later only apically to allow the close-packing with functional teeth while still emerging (at least for the midposterior cheek teeth). For anterior maxillary teeth (MPEF-PV 3211 and 3809; Figs 2, 3), the presence of tooth crypts anterior to the first tooth positions allows for a possible anteriorto-posterior direction of migration of developing teeth together with the apical and labial direction. The ordering of the toothrow as a successive replacement series and a wave-like replacement pattern in a fore-aft direction previously discussed in heterodontosaurids (Gow 1975; Hopson 1980; Norman et al. 2011; Sereno 2012) also appears to pertain to Manidens.

The first descriptions of the dental replacement in heterodontosaurid specimens addressed the external direction of replacement waves (Gow 1975; Hopson 1975), thereby inviting inference of whether these are oriented in a fore-to-aft or aft-to-front direction on naked eye observation based on the Z-spacing (Edmund 1969). This was attempted using the available data for Manidens, but it was not possible due to heterodonty, low tooth count, taphonomic biases, the possible dimorphic tooth in position D3, and the inconclusive relationship of the anterior teeth with the hypothetical replacement series of the midposterior dentitions. The average $\mathrm{Z}$-spacing of functional teeth per replacement wave was 2.3 for the maxilla of MPEF-PV 3211, 2.25 for the right dentary and 1.6 for the left dentary; 2 for the maxillary dentition of MPEF-PV 3809; and unknown for MPEF-PV 3808. With this, a foreto-aft replacement is identified in odd and even tooth positions of both dentaries of MPEF-PV 3211 (counting from the D4 to the last tooth), while an aft-to-front direction is inferred if evaluating the even positions of MPEFPV 3809, and a fore-to-aft direction if considering the odd tooth positions (counting from the M3 to the last tooth). No hypothesis can be tested regarding the replacement direction of teeth for the fragmentary dentitions of the maxillary toothrow in MPEF-PV 3211 and the dentary toothrow in MPEF-PV 3808. Further work addressing tooth replacement in reptiles shows that the pattern is more complicated than previously thought: the replacement waves may not be constant in direction or rhythm in the tooth line or during ontogeny (Demar 1972; Osborn 1975; Whitlock \& Richman 2013). The variation in Z-spacing and the variable external replacement direction in different specimens of Manidens indicate that replacement was complex in the species, complicated by: (1) the preserved replacement picture at the time of death; (2) whether the maxillary or dentary dentition is being evaluated; (3) the maintenance of the same replacement rhythm along the entire toothrow (replacement of the enlarged caniniform may affect the replacement rate in the anterior dentition); and (4) ontogeny (involving the increase in size and number of teeth in the toothrow and the possible cessation of replacement at maturity). The practice of inferring the external direction of replacement based on Z-spacing is problematic, depends on many factors, and can lead to confusion when describing dental replacement in species with a low tooth count (as occurring with Manidens and others in Heterodontosauridae), while it is purely descriptive when tomographic information and $3 \mathrm{D}$ reconstruction of replacement teeth at different stages of development are available.

Furthermore, it is interesting to note that there appears to be a general dichotomy concerning patterns of tooth replacement in dinosaurs that generally matches the traditional division of Dinosauria into the clades Ornithischia and Saurischia. Saurischians characteristically display patterns of replacement consistent with an 'every other' or alternating pattern (D’Emic et al. 2013; Schwarz et al. 2015). Ornithischians, in contrast, appear to replace their teeth primarily in a wave-type pattern (Ostrom 1966; Gow 1975, 1990; Dalla Vecchia 2009; Butler et al. 2012; Tanoue et al. 2012; Mallon \& Anderson 2014). However, some ankylosaurids replaced their teeth in an alternating pattern (Panoplosaurus; Mallon \& Anderson 2014), as was 
also the case in the dental batteries of Ceratopsidae and Hadrosauridae (and possibly basal iguanodontians), while comparatively little is known about patterns of replacement in the basal members of either clades. No studies have been done on replacement patterns in basal saurischians, and the two studies on basal ornithischians (both on Lesothosaurus) are equivocal with regard to the pattern (Crompton \& Attridge 1987; Sciscio et al. 2017). Nonetheless, alternating or wave-like patterns of tooth replacement in Dinosauria were never addressed in relation to body size, jaw mechanisms, the degree to which ornithischians and saurischians are thought to have used oral versus gastric processing, or to the appearance of other craniomandibular states in the phylogeny that describe the evolutionary specialization of a certain diet. This is potentially an interesting avenue for further study, given the different developmental mechanics and evolutionary history apparently underlying these two different patterns of replacement.

\section{Functional and evolutionary implications of tooth replacement in Manidens}

Tooth replacement in polyphyodont dentitions (including non-mammalian amniotes) is related to growth, changing diet during ontogeny, and wear development (Berkovitz \& Shellis 2016). Manidens shows evidence of the addition of new teeth in the posterior part of the toothrow, increasing tooth size during ontogeny, changes in enamel micromorphology that potentially suggest dietary shifts during ontogeny, and the development of wear in teeth independent from the slow and continuous tooth replacement (Becerra \& Pol 2020). During the evolution of herbivorous dinosaur lineages, intensive herbivory was enhanced by the appearance of high-crowned teeth in polyphyodont dentitions with an increase in the replacement rate, overcoming the disadvantage of losing the functionality of teeth due to increased wear (Erickson 1996; D'Emic et al. 2013). Although Manidens shows a unique combination of features that enhance intraoral food processing such as the closely packed toothrow with double occlusion and high crowns at the mid toothrow, it also exhibits a low rate of both dental replacement and wear development consistent with other primitive craniomandibular features and jaw movements, common in other early ornithischians (Becerra et al. 2014, 2018, Becerra \& Pol 2020).

The evolution of herbivory requires the appearance of numerous physiological, anatomical, and behavioural adaptations, a transition made in all dinosaur lineages through a hypothetical omnivorous ancestor (Barrett \& Rayfield 2006; Barrett 2014). These include innovative craniomandibular modifications to gather and efficiently process food (tooth morphology, jaw musculature), postcranial modifications to assist in food collection with decreased energy expenditure (e.g. long necks), and modifications to the gastrointestinal tract to help digestion (gizzards, fermentative digestion, gastroliths; Farlow 1987, Kobayashi et al. 1999; Mackie 2002; Sereno \& Wilson 2005; Wings \& Sander 2007; Cerda 2008; Fritz et al. 2011; Hummel \& Clauss 2011; Barrett 2014; Wings 2014; Erickson et al. 2016; Nabavizadeh 2020). When dental evolution is considered in herbivorous lineages of amniotes, high rates of oral processing and food ingestion are linked to the appearance of high-crowned dentitions, in which precise dental occlusion is enabled by extensive wear, and hardened dental tissues increase resistance (Janis \& Fortelius 1988; Sander 1999; Kaiser et al. 2013; Erickson et al. 2016; Bramble et al. 2017; Becerra \& Pol 2020). Dental types within this definition can be divided in three subgroups: (1) packed dentitions with limited growth, polyphyodont with low replacement rate for Heterodontosaurus and low to average replacement rates for non-hadrosaurid Dryomorpha, early ceratopsians, and Neosauropoda (Norman \& Weishampel 1985; Weishampel \& Norman 1989; Norman 2004; Sereno \& Wilson 2005; Tanoue et al. 2009; Tanoue et al. 2012; Norman et al. 2011; Sereno 2012; Strickson et al. 2016), and diphyodont for some ungulates and most rodents (Damuth \& Janis 2011; Erickson 2014); (2) tightly packed dental batteries consisting of teeth with limited growth but a continuous grinding surface, in an apicobasally replaced polyphyodonty in ceratopsids, hadrosaurids and rebbachisaurids (Dodson et al. 2004; Horner et al. 2004; Sereno \& Wilson 2005; Bell et al. 2009), distomesially replaced for manatees and some rodents (polyphyodonty), and elephantimorph proboscideans (delayed diphyodonty; Asher \& Lehmann 2008; Beatty et al. 2012; Rodrigues et al. 2012; Sanders 2018); and (3) partial or complete elodonty (ever-growing teeth) as in several mammalian groups (Ferigolo 1985; Madden 2014). Reaching a detailed understanding of the evolution of highly specialized dentitions necessitates the evaluation of early stages of dental anatomy in basal species less well-adapted to herbivory and of the possible sequence of craniomandibular transformations related to herbivory in a phylogenetic context (Stirton 1947; Erickson et al. 2016; Strickson et al. 2016). In this matter, it is worth noting that, for dinosaur lineages except Heterodontosauridae, packed polyphyodont dentitions with a low-middle replacement rate correspond to the previous stage of development of dental batteries with a high rate of replacement.

Although a low rate of tooth replacement characterizes Heterodontosauridae (Norman et al. 2011; Butler et al. 2012; Sereno 2012), the stage of packed polyphyodont dentition with a slow but continuous replacement represented by Manidens differs from that of more basal (Fruitadens, Tianyulong, Echinodon) and more derived (Lycorhinus, Abrictosaurus, Heterodontosaurus) species of the clade 
Heterodontosauridae (Zheng et al. 2009; Butler et al. 2012; Sereno 2012; Becerra et al. 2014). While primitive species in Heterodontosauridae show a well-spaced postcaniniform dentition with low crowns subequal in height (low degree of height-width heterodonty) and poorly developed vertical wear (no intraoral processing), more derived species show packed dentitions with higher crowns in the middle of the postcaniniform dentition (higher degree of heightwidth heterodonty) and more developed oblique wear (intraoral food processing). The most advanced stage for oral processing in Heterodontosauridae, represented by Heterodontosaurus (Norman et al. 2011), has the highest degree of height-width heterodonty (only a small first crown and a low and wide last crown, while the rest of the postcaninifom teeth are extremely high) and a systematic wear that provides sharp edges and a grinding surface for chewing. At least for Heterodontosauridae, the evolutionary pattern explaining the appearance of hypsodonty is related to the increase of the height-width postcaniniform heterodonty with a differential increase in height. This is supported by the low height-width postcaniniform heterodonty in early species such as Fruitadens, the high crowns occupying only the middle region in Manidens, and even higher crowns occupying most of the dentition in Heterodontosaurus and Lycorhinus (Norman et al. 2011; Sereno 2012; Becerra et al. 2014). This study strongly indicates that the adaptation to herbivory in Heterodontosauridae occurred with the increase in hypsodonty and the close-packing of dentition together with the appearance of intraoral food processing (extensive wear development) but without reaching a high rate of dental replacement and/or the development of a longer toothrow (Becerra et al. 2018), contrasting with the dental evolution of Ceratopsia and Ornithopoda. Comparison of the occurrence and order of morphological and functional transformations between unrelated lineages allows us to identify common mechanisms of adaption to major evolutionary transitions; in this case, adapting to herbivory, one of the most important and recurring transformations in terrestrial vertebrates (Madden 2014). Tooth replacement, however, is an important but poorly explored aspect in studies that tackle the evolution of herbivory in Ornithischia. This topic, however, is of great importance, as shown by the repeated cases of modification of the plesiomorphic replacement pattern in different ways, but ultimately resulting in similar rapid and uninterrupted replacement in different ornithischian lineages.

\section{CONCLUSIONS}

New information from $\mu \mathrm{CT}$ and $3 \mathrm{D}$ reconstructions not only allows elucidation of the most likely replacement pattern for Manidens, but also provides evidence of asynchronous replacement, the first evidence ever of a replacement tooth for the enlarged caniniform, and possible intraspecific dimorphism, significantly increasing our knowledge of the dentition of the species and of Heterodontosauridae in general. We have also gained new insight into the dentary dentition based on features of MPEF-PV 3211 and 3808: it begins with the enlarged caniniform and is followed posteriorly by: a slight postcaniniform diastema; a small conical tooth with no carinae; a possibly dimorphic small caniniform tooth; a D4 with intermediate features between a caniniform tooth and the midposterior dentary dentition (with small denticles and a large apex); and the asymmetric diamond-shaped succeeding toothrow with height-width heterodonty. Together with previous studies (Becerra et al. 2014, 2018), the anatomy of the maxillary and dentary dentitions of Manidens is now completely described. Only a few anatomical (i.e. existence of a small precaniniform dentary tooth, morphology of the premaxillary dentition) and palaeobiological uncertainties (i.e. concrete evidence supporting intraspecific dimorphism) in the dentition of Manidens are yet to be resolved. However, it is apparent that the species Manidens condorensis shows a unique dentition in Ornithischia, even compared with its relatives in Heterodontosauridae.

The arrangement of the different stages of replacement teeth and the differential wear of functional teeth demonstrate that Manidens possesses a polyphyodont dentition with continuous and wave-like replacement, in which several replacement waves take place at the same time, a Zspacing probably ranging between 2 and 3 teeth: a pattern congruent across the midposterior dentition of the three specimens here described. Asynchronous replacement was recently described for Lesothosaurus diagnosticus (Sciscio et al. 2017) and is widely identified in reptiles (Edmund 1960), but had never been noted in heterodontosaurids, making Manidens the first species in this lineage to show this feature. The asynchronous eruption sequences between replacement waves acting in right and left toothrows in MPEF-PV 3211, and the incorporation of new teeth to the toothrow posteriorly during ontogeny are strongly supported in Manidens. In addition, Manidens provides the first evidence in Heterodontosauridae of active and asynchronous tooth replacement for the enlarged caniniform, and although the replacement rate for this caniniform was probably slower than for the cheek dentition, further research is needed to support this hypothesis and to determine whether the replacement of this tooth affects the replacement rate of the anterior cheek dentition. The dental replacement in the midposterior cheek dentition does not disrupt the concave-convex relationship of successive crowns, due to the presence of the mesial cavity, which permits an accurate and tight eruption between neighbouring teeth without affecting the close packing of the toothrow. Although two of the 
three specimens show clear size differences, they cannot be compared in terms of replacement rate due to poor preservation. The sectioning of isolated maxillary and dentary teeth demonstrates features (i.e. the presence of a basal concavity related to root resorption) supporting tooth replacement (i.e. signs of activity of odontoclasts), and, more importantly, indicating that dental replacement is independent of wear development for Manidens.

Although the occurrence of omnivory-herbivory corresponds to the most probable ancestral state, the specialization of the masticatory apparatus to herbivory occurs independently and possibly several times in each major group of Ornithischia (Barrett 2000; Barrett et al. 2010). The homoplastic occurrence of dental batteries with alternate replacement in Ceratopsidae and Hadrosauridae is a frequently cited evolutionary adaptation to highly specialized herbivory in amniotes (Sander 1997; Bell et al. 2009). However, the evolutionary transition from a plesiomorphic wave-like replacement pattern with a lower replacement rate to an alternating, higher replacement rate, along with other dental features (i.e. enamel asymmetry, close packing of successive dental families, elimination of the alveolar space between functional teeth, enlargement of the toothrow) have been poorly explored in most generalized phylogenies (Sereno 1999; Xu et al. 2002, 2006; Butler et al. 2008b; Tanoue et al. 2012; Boyd 2015; Strickson et al. 2016). The assessment of tooth replacement is only briefly addressed in basal species of major ornithischian lineages, but its inclusion in a phylogenetic scenario would allow increased understanding of craniomandibular specialization to herbivory within each group, and comparison of the order of appearance of this specialization between different lineages within and outside of Ornithischia. At least for Heterodontosauridae, a complete revision and update incorporating new methodologies (i.e. $\mu \mathrm{CT}$ scanning) is needed to assess the evolution of tooth replacement together with other dental and cranial features related to herbivory.

Acknowledgements. Fieldwork was possible thanks to the authorities of the Secretaría de Cultura de la Provincia del Chubut. Fieldwork and research were supported by Agencia Nacional de Promoción Científica y Tecnológica (ANPCyT, Argentina), under Grants PICT 2017-1897 (to MGB), PICT 1288 and 0808 (to DP); by Deutsche Forschungsgemeinschaft (DFG, Germany), under Grant RA1012/9-1 (to Dr O. W. M. Rauhut); and National Science Foundation (NSF, USA), under Grants DEB 0946430 and DEB 1068089 (to Dr G. Rougier). The Deutscher Akademischer Austauschdienst (DAAD) provided funding for MGB to travel to Germany (ID 57130097). The Staatliche Naturwissenschaftliche Sammlungen Bayerns (Munich) and the staff of this institution are thanked for allowing the use of the $\mu \mathrm{CT}$ facilities. The cooperation of Dr O. W. M. Rauhut (Bayerische Staatssammlung für Paläontologie und Geologie, Munich, Germany) with the DAAD project and his kind help given to MGB during the trip to Germany are appreciated. The kind help of Dr Y. Herrera (Universidad Nacional de La Plata) is also appreciated. SEM was carried out thanks to ALUAR Aluminio Argentino SAIC facilities (Puerto Madryn, Chubut Province), with the help of J. Groizard and M. Luquet. The kind contribution of IDECh Instituto de Diagnóstico del Este de Chubut S.R.L. (Trelew, Chubut) to the preliminary CT scanning on MPEF-PV 3808 is also appreciated. Dr D. Schwarz and an anonymous referee are here thanked for their comments, which significantly enhanced an earlier draft of this manuscript.

\section{DATA ARCHIVING STATEMENT}

The $\mu$ CT scan dataset used for this study is archived in the collection of the Museo Paleontológico Egidio Feruglio and also on MorphoSource: MPEF:PV:3211, M68473-123445 (partial skeleton): https://doi.org/10.17602/m2/m123445; MPEF:PV:3809, M68474-123447 (cranial fragments): https://doi.org/10.17602/ $\mathrm{m} 2 / \mathrm{m} 123447$

Editor. Stephan Lautenschlager

\section{REFERENCES}

ANDERSON, R. A. and VITT, L. J. 1990. Sexual selection versus alternative causes of sexual dimorphism in teiid lizards. Oecologia, 84, 145-157.

ASHER, R. J. and LEHMANN, T. 2008. Dental eruption in afrotherian mammals. BMC Biology, 6, 1-14.

BARRETT, P. M. 2000. Prosauropod dinosaurs and iguanas: speculations on the diets of extinct reptiles. 42-78. In SUES, H.D. (ed.) Evolution of herbivory in terrestrial vertebrates: Perspectives from the fossil record. Cambridge University Press, $256 \mathrm{pp}$.

— 2014. Paleobiology of herbivorous dinosaurs. Annual Review of Earth \& Planetary Sciences, 42, 207-230.

— and RAYFIELD, E. J. 2006. Ecological and evolutionary implications of dinosaur feeding behaviour. Trends in Ecology \& Evolution, 21, 217-224.

— BUTLER, R. J. and NESBITT, S. J. 2010. The roles of herbivory and omnivory in early dinosaur evolution. Earth of Environmental Science Transactions of the Royal Society of Edinburgh, 101, 383-396.

BEATTY, B. L., VitKOVSKI, T., LAMBERT, O. and MACRINI, T. E. 2012. Osteological associations with unique tooth development in manatees (Trichechidae, Sirenia): a detailed look at modern Trichechus and a review of the fossil record. The Anatomical Record, 295, 1504-1512.

BECERRA, M. G. and POL, D. 2020. The enamel microstructure of Manidens condorensis: new hypotheses on the ancestral state and evolution of enamel in Ornithischia. Acta Palaeontologica Polonica, 65, 59-70.

— MARSiCANO, C. A. and RAUHUT, O. W. M. 2014. The dentition of Manidens condorensis (Ornithischia; Heterodontosauridae) from the Jurassic Cañadón Asfalto Formation of Patagonia: morphology, heterodonty and the use of statistical methods for identifying isolated teeth. Historical Biology, 26, 480-492. 
RAUHuT, O. W. M. and CERDA, I. A. 2016. New heterodontosaurid remains from the Cañadón Asfalto formation: cursoriality and the functional importance of the pes in small heterodontosaurids. Journal of Paleontology, 90, 555-577.

— RÖSSNER, G. E. and RAUHUT, O. W. M. 2018. Heterodonty and double occlusion in Manidens condorensis: a unique adaptation in an Early Jurassic ornithischian improving masticatory efficiency. The Science of Nature, 105, 41.

BELL, P. R., SNIVELY, E. and SHYCHOSKI, L. 2009. A comparison of the jaw mechanics in hadrosaurid and ceratopsid dinosaurs using finite element analysis. The Anatomical Record, 292, 1338-1351.

BENNETT, D. and HOFFMANN, R. S. 1999. Equus caballus Linnaeus, 1758. Horse. Mammalian Species, 628, 1-14.

BERKOVITZ, B. K. 2000. Tooth replacement patterns in nonmammalian vertebrates. 186-200. In TEAFORD, M. F., SMITH, M. M. and FERGUSON, M. W. J. (eds). Development, function and evolution of teeth. Cambridge University Press, $322 \mathrm{pp}$.

- and SHELLIS, P. 2016. The teeth of non-mammalian vertebrates. Academic Press, $343 \mathrm{p}$.

BONAPARTE, J. F. 1979. Dinosaurs: a Jurassic assemblage from Patagonia. Science, 205, 1377-1379.

BOYD, C. A. 2015. The systematic relationships and biogeographic history of ornithischian dinosaurs. PeerJ, 3, e1523.

BRAMBLE, K., LEBLANC, A. R., LAMOUREUX, D. O., WOSIK, M. and CURRIE, P. J. 2017. Histological evidence for a dynamic dental battery in hadrosaurid dinosaurs. Scientific Reports, 7, 1-13.

BUtLER, R. J., PORRO, L. B. and NORMAN, D. B. 2008a. A juvenile skull of the primitive ornithischian dinosaur Heterodontosaurus tucki from the 'Stormberg' of southern Africa. Journal of Vertebrate Paleontology, 28, 702-711.

- UPCHURCH, P. and NORMAN, D. B. 2008b. The phylogeny of the ornithischian dinosaurs. Journal of Systematic Palaeontology, 6, 1-40.

— PORRO, L. B., GALton, P. M., ChiapPe, L. M., HENDERSON, D. M. and ERICKSON, G. M. 2010. Lower limits of ornithischian dinosaur body size inferred from a new Upper Jurassic heterodontosaurid from North America. Proceedings of the Royal Society B, 277, 375-381.

2012. Anatomy and cranial functional morphology of the small-bodied dinosaur Fruitadens haagarorum from the Upper Jurassic of the USA. PLoS One 7 (4), e31556.

BUTTON, K., YOU, H., KIRKLAND, J. I. and ZANNO, L. 2017. Incremental growth of therizinosaurian dental tissues: implications for dietary transitions in Theropoda. PeerJ, 5, e4129.

CAMILLERI, C. and SHINE, R. 1990. Sexual dimorphism and dietary divergence: differences in trophic morphology between male and female snakes. Copeia, 1990, 649-658.

CERDA, I. A. 2008. Gastroliths in an ornithopod dinosaur. Acta Palaeontologica Polonica, 53, 351-355.

CHARIG, A. J. and CROMPTON, A. W. 1974. The alleged synonymy of Lycorhinus and Heterodontosaurus. Annals of the South African Museum, 64, 167-189.

CHEN, J., LEBLANC, A. R. H., JIN, L., HUANG, T. and REISZ, R. R. 2018. Tooth development, histology, and enamel microstructure in Changchunsaurus parvus: implications for dental evolution in ornithopod dinosaurs. PLoS One, 13, e0205206.

COLBERT, K. H. 1981. A primitive ornithischian dinosaur from the Kayenta formation of Northern Arizona. Museum of Northern Arizona Press Bulletin Series, 53, 1-61.

CROMPTON, A. W. and ATTRIDGE, J. 1986. Masticatory apparatus of the larger herbivores during the Late Triassic and Early Jurassic times. 223-236. In P A I AN, K. (ed.) The beginning of the Age of Dinosaurs: Faunal change across the TriassicJurassic boundary. Cambridge University Press, 404 pp.

CÚNEO, R., RAMEZANI, J., SCASSO, R., POL, D., ESCAPA, I., ZAVATTIERI, A. M. and BOWRING, S. A. 2013. High-precision $\mathrm{U}-\mathrm{Pb}$ geochronology and a new chronostratigraphy for the Cañadón Asfalto Basin, Chubut, Central Patagonia: implications for terrestrial faunal and floral evolution in Jurassic. Gondwana Research, 24, 1267-1275.

D’EMIC, M. D., Whitlock, J. A., SMITH, K. M., FISHER, D. C. and WILSON, J. A. 2013. Evolution of high tooth replacement rates in sauropod dinosaurs. PLoS One, 8, e69235.

DALLA VECCHIA, F. M. 2009. Tethyshadros insularis, a new hadrosauroid dinosaur (Ornithischia) from the Upper Cretaceous of Italy. Journal of Vertebrate Paleontology, 29, 11001116.

DAMUTH, J. and JANIS, C. M. 2011. On the relationship between hypsodonty and feeding ecology in ungulate mammals, and its utility in palaeoecology. Biological Reviews, 86, 733-758.

DEMAR, R. 1972. Evolutionary implications of Zahnreihen. Evolution, 26, 435-450.

DODSON, P., FORSTER, C. A. and SAMPSON, S. D. 2004. Ceratopsidae. 494-514. In WEISHAMPEL, D. B., DODSON, P. and OSMÓLSKA, H. (eds). The Dinosauria. 2nd edn. University of California Press, 776 pp.

EDMUND, A. G. 1960. Tooth replacement phenomena in the lower vertebrates. Contributions of the Royal Ontario Museum, Life Sciences Division, 52, 1-90.

- 1962. Sequence and rate of tooth replacement in the Crocodilia. Contributions of the Royal Ontario Museum, Life Sciences Division, 56, 1-42.

1969. Dentition. 117-200. In GANS, C. and PARSONS, T. S. (eds) Biology of the reptilia. Vol. 1 Morphology A. Academic Press, 373 pp.

ERICKSON, G. M. 1996. Incremental lines of von Ebner in dinosaurs and the assessment of tooth replacement rates using growth line counts. Proceedings of the National Academy of Sciences, 93, 14623-14627.

ERICKSON, K. L. 2014. Prairie grass phytolith hardness and the evolution of ungulate hypsodonty. Historical Biology, 26, 737-744.

ERICKSON, G. M., SIDEBOTTOM, M. A., CURRY, J. F., KAY, D. I., KUHN-HENDRICKS, S., NORELL, M. A., SAWYER, W. G. and KRICK, B. A. 2016. Paleo-tribology: development of wear measurement techniques and a threedimensional model revealing how grinding dentitions self-wear to enable functionality. Surface Topography: Metrology \& Properties, 4 (2), 024001. 
ESCAPA, I. H., STERLI, J., POL, D. and NICOLI, L. 2008. Jurassic tetrapods and flora of Cañadón Asfalto formation in Cerro Condor area, Chubut Province. Revista de la Asociación Geológica Argentina, 63, 613-624.

FARLOW, J. O. 1987. Speculations about the diet and digestive physiology of herbivorous dinosaurs. Paleobiology, 13, 60-72.

FEDOROV, A., BEICHEL, R., KALPATHY-CRAMER, J., FINET, J., FILliON-ROBIN, J. C., PUJOL, S., BAUER, C., JENNINGS, D., FENNESSY, F., SONKA, M. and BUATTI, J. 2012. 3D Slicer as an image computing platform for the quantitative imaging network. Magnetic Resonance Imaging, 30, 1323-1341.

FERIGOLO, J. 1985. Evolutionary trends of the histological pattern in the teeth of Edentata (Xenarthra). Archives of Oral Biology, 30, 71-82.

FRITZ, J., HUMMEL, J., KIENZLE, E., WINGS, O., STREICH, W. J. and CLAUSS, M. 2011. Gizzard vs. teeth, it's a tie: food-processing efficiency in herbivorous birds and mammals and implications for dinosaur feeding strategies. Paleobiology, 37, 577-586.

FUENZALIDA, M., ILLANES, J., LEMUS, R., GUERRERO, A., OYARZÚN, A., ACUÑA, O. and LEMUS, D. 1999. Microscopic and histochemical study of odontoclasts in physiologic resorption of teeth of the polyphyodont lizard, Liolaemus gravenhorsti. Journal of Morphology, 242, 295-309.

GALTON, P. M. 1978. Fabrosauridae, the basal family of ornithischian dinosaurs (Reptilia: Ornithopoda). Paläontologische Zeitschrift, 52, 138-159.

GINGERICH, P. D. 1981. Variation, sexual dimorphism, and social structure in the early Eocene horse Hyracotherium (Mammalia, Perissodactyla). Paleobiology, 7, 443-455.

GOW, C. E. 1975. A new heterodontosaurid from the Red Beds of South Africa showing clear evidence of tooth replacement. Zoological Journal of the Linnean Society of London, 57, 335339.

- 1990. A tooth-bearing maxilla referable to Lycorhinus angustidens Haughton 1924 (Dinosauria: Ornithischia). Annals of the South African Museum, 99, 367-380.

GRANT, A. 1982. The use of tooth wear as a guide to the age of domestic animals. 91-108. In WILSON, B., GRIGSON, C. and PAYNE, S. (eds). Ageing and sexing animal bones from archaeological sites. British Archaeological Records International Series, 109.

GREER, A. E. 1991. Tooth number in the scincid lizard genus Ctenotus. Journal of Herpetology, 25, 473-477.

GREICO, T. M. and RICHMAN, J. M. 2018. Coordination of bilateral tooth replacement in the juvenile gecko is continuous with in ovo patterning. Evolution \& Development, 20, 51-64.

HARVEY, P. H., KAVANAGH, M. and CLUTTONBROCK, T. H. 1978. Sexual dimorphism in primate teeth. Journal of Zoology, 186, 475-485.

HERREL, A., VAN DAMME, R. and DE VREE, F. 1995. Sexual dimorphism of head size in Podarcis hispanica atrata: testing the dietary divergence hypothesis by bite force analysis. Netherlands Journal of Zoology, 46, 253-262.

HOLE, S. L. 2015. Wolf teeth and their extraction. Equine Veterinary Education, 28, 344-351.
HOPSON, J. A. 1975. Generic separation of ornithischian dinosaurs Lycorhinus and Heterodontosaurus from Stormberg Series (Upper Triassic) of South-Africa. South African Journal of Science, 71, 302-305.

- 1980. Tooth function and replacement in early Mesozoic ornithischian dinosaurs: implications for aestivation. Lethaia, 13, 93-105.

HORNER, J. R., WEISHAMPEL, D. B. and FORSTER, C. A. 2004. Hadrosauridae. 438-463. In WEISHAMPEL, D. B., DODSON, P. and OSMÓLSKA, H. (eds) The Dinosauria, second edition. University of California Press, $776 \mathrm{pp}$.

HÜBNER, T. R. and RAUHUT, O. W. M. 2010. A juvenile skull of Dysalotosaurus lettowvorbecki (Ornithischia: Iguanodontia), and implications for cranial ontogeny, phylogeny, and taxonomy in ornithopod dinosaurs. Zoological Journal of the Linnean Society, 160, 366-396.

HUMMEL, J. and CLAUSS, M. 2011. Sauropod feeding and digestive physiology. 11-33. In KLEIN, N., REMES, K., GEE, C. T. and SANDER, P. M. (eds) Biology of the sauropod dinosaurs: Understanding the life of giants. Indiana University Press, Bloomington, IN, $344 \mathrm{pp}$.

JANIS, C. M. and FORTELIUS, M. 1988. On the means whereby mammals achieve increased functional durability of their dentitions, with special reference to limiting factors. Biological Reviews, 63, 197-230.

KAISER, T. M., MÜlleR, D. W., FORTEliUS, M., SCHULZ, E., CODRON, D. and CLAUSS, M. 2013. Hypsodonty and tooth facet development in relation to diet and habitat in herbivorous ungulates: implications for understanding tooth wear. Mammal Review, 43, 34-46.

KOBAYASHI, Y., LU, J. C., DONG, Z. M., BARSBOLD, R., AZUMA, Y. and TOMIDA, Y. 1999. Herbivorous diet in an ornithomimid dinosaur. Nature, 402, 480-481.

LEBLANC, A. R., REISZ, R. R., EVANS, D. C. and BAILLEUL, A. M. 2016. Ontogeny reveals function and evolution of the hadrosaurid dinosaur dental battery. BMC Evolutionary Biology, 16, 152.

LEUTENEGGER, W. and KELLY, J. T. 1977. Relationship of sexual dimorphism in canine size and body size to social, behavioral, and ecological correlates in anthropoid primates. Primates, 18, 117-136.

MACFADDEN, B. J. 2000. Cenozoic mammalian herbivores from the Americas: reconstructing ancient diets and terrestrial communities. Annual Review of Ecology \& Systematics, 31, 33-59.

MACKIE, R. I. 2002. Mutualistic fermentative digestion in the gastrointestinal tract: diversity and evolution. Integrative \& Comparative Biology, 42, 319-326.

MADDEN, R. H. 2014. Hypsodonty in mammals: Evolution, geomorphology and the role of earth surface processes. Cambridge University Press.

MALLON, J. C. and ANDERSON, J. S. 2014. The functional and paleoecological implications of tooth morphology and wear for the megaherbivorous dinosaurs from the Dinosaur Park Formation (Upper Campanian) of Alberta, Canada. PLoS One, 9, e98605.

McPherson, F. J. and ChenOWETH, P. J. 2012. Mammalian sexual dimorphism. Animal Reproduction Science, 131, 109-122. 
MILES, A. E. W. 1963. The dentition in the assessment of individual age in skeletal material. 191-209. In BROTHWELL, D. R. (ed.) Dental anthropology. Pergamon Press.

MOLNAR, R. E. 1977. Analogies in the evolution of combat and display structures in ornithopods and ungulates. Evolutionary Theory, 3, 165-190.

NABAVIZADEH, A. 2020. New reconstruction of cranial musculature in ornithischian dinosaurs: implications for feeding mechanisms and buccal anatomy. The Anatomical Record, 303, 347-362.

NORMAN, D. B. 2004. Basal Iguanodontia. 413-437. In WEISHAMPEL, D. B., DODSON, P. and OSMÓLSKA, H. (eds). The Dinosauria. 2nd edn. University of California Press, 776 pp.

— and WEISHAMPEL, D. B. 1985. Ornithopod feeding mechanisms: their bearing on the evolution of herbivory. American Naturalist, 126, 151-164.

— CROMPtON, A. W., BUtler, R. J., PORRO, L. B. and CHARIG, A. J. 2011. The Lower Jurassic ornithischian dinosaur Heterodontosaurus tucki Crompton and Charig 1962: cranial anatomy, functional morphology, taxonomy, and relationships. Zoological Journal of the Linnean Society, 162, 182279.

OSBORN, J. W. 1971. The ontogeny of tooth succession in Lacerta vivipara Jacquin (1787). Proceedings of the Royal Society $B, 179,261-289$.

— 1975. Tooth replacement: efficiency, patterns and evolution. Evolution, 29, 180-186.

OSTROM, J. H. 1966. Functional morphology and evolution of the ceratopsian dinosaurs. Evolution, 20, 290-308.

PLAVCAN, J. M. 2001. Sexual dimorphism in primate evolution. American Journal of Physical Anthropology, 116, 25-53.

_ and VAN SCHAIK, C. P. 1993. Canine dimorphism. Evolutionary Anthropology: Issues, News, \& Reviews, 2, 208-214.

POL, D. and RAUHUT, O. W. M. 2012. A Middle Jurassic abelisaurid from Patagonia and the early diversification of theropod dinosaurs. Proceedings of the Royal Society B, 279, 3170-3175.

— a and BECERRA M. G. 2011. A Middle Jurassic heterodontosaurid dinosaur from Patagonia and the evolution of heterodontosaurids. Naturwissenschaften, 98, 369379.

PORRO, L. B., BUTLER, R. J., BARRETT, P. M., MOORE-FAY, S. and ABEL, R. L. 2011. New heterodontosaurids specimens from the Lower Jurassic of southern Africa and the early ornithischian dinosaur radiation. Earth \& Environmental Transactions of the Royal Society of Edinburgh, 101, 351-366.

WITMER, L. M. and BARRETT, P. M. 2015. Digital preparation and osteology of the skull of Lesothosaurus diagnosticus (Ornithischia: Dinosauria). PeerJ, 3, e1494.

RAUHUT, O. W. M. and LOPEZ-ARBARELlo, A. 2008. Archosaur evolution during the Jurassic: a southern perspective. Revista de la Asociación Geológica Argentina, 63, 557-585.

— PUERTA, P. and MARTÍN, T. 2001. Jurassic vertebrates from Patagonia. Journal of Vertebrate Paleontology, 21, 91a.
RODRigueS, H. G., SOlÉ, F., CHARles, C., TAFFOREAU, P., VIANEY-LIAUD, M. and VIRIOT, L. 2012. Evolutionary and biological implications of dental mesial drift in rodents: the case of the Ctenodactylidae (Rodentia, Mammalia). PLoS One, 7, e50197.

SAlTEL, F., Destaing, O., BARD, F., EICHERT, D. and JURDIC, P. 2004. Apatite-mediated actin dynamics in resorbing osteoclasts. Molecular Biology of the Cell, 15, 52315241.

SANDER, P. M. 1997. Teeth and jaws. 717-725. In CURRIE, P. J. and PADIAN, K. (eds) Encyclopedia of dinosaurs. Academic Press, 869 pp.

1999. The microstructure of reptilian tooth enamel: terminology, function, and phylogeny. Münchner Geowissenschaftliche Abhandlungen, Reihe A, Geologie \& Palaontologie, 38, 1-103.

SANDERS, W. J. 2018. Horizontal tooth displacement and premolar occurrence in elephants and other elephantiform proboscideans. Historical Biology, 30, 137-156.

SASAKI, T., MOTEGI, N., SUZUKI, H., WATANABE, C., TADOKORO, K., YANAGISAWA, T. and HIGASHI, S. 1988. Dentin resorption mediated by odontoclasts in physiological root resorption of human deciduous teeth. Developmental Dynamics, 183, 303-315.

SCHWARZ, D., KOSCH, J. C. D., FRITSCH, G. and HILDEBRANDT, T. 2015. Dentition and tooth replacement of Dicraeosaurus hansemanni (Dinosauria, Sauropoda, Diplodocoidea) from the Tendaguru Formation of Tanzania. Journal of Vertebrate Paleontology, 25, e1008134.

SCISCIO, L., KNOLL, F., BORDY, E. M., DE KOCK, M. O. and REDELSTORFF, R. 2017. Digital reconstruction of the mandible of an adult Lesothosaurus diagnosticus with insight into the tooth replacement process and diet. PeerJ, 5, e3054.

SERENO, P. C. 1991. Lesothosaurus, "fabrosaurids", and the early evolution of Ornithischia. Journal of Paleontology, 11, 168-197.

1999. The evolution of dinosaurs. Science, 284, 2137-2147.

2012. Taxonomy, morphology, masticatory function and phylogeny of heterodontosaurid dinosaurs. ZooKeys, 226, 1225.

- and WILSON, J. A. 2005. Structure and evolution of a sauropod tooth battery. 157-177. In CURRY ROGERS, K. A. and WILSON, J. A. (eds). The sauropods: Evolution and paleobiology. University of California Press, $349 \mathrm{pp}$.

SHINE, R. 1989. Ecological causes for the evolution of sexual dimorphism: a review of the evidence. The Quarterly Review of Biology, 64, 419-461.

— 1991. Intersexual dietary divergence and the evolution of sexual dimorphism in snakes. The American Naturalist, 138, 103-122.

STIRTON, R. A. 1947. Observations on evolutionary rates in hypsodonty. Evolution, 1, 32-41.

STRICKSON, E., PRIETO-MÁRQUEZ, A., BENTON, M. J. and STUBBS, T. L. 2016. Dynamics of dental evolution in ornithopod dinosaurs. Scientific Reports, 6, 28904.

SUllivAN, C., REISZ, R. R. and SMITH, R. M. 2003. The Permian mammal-like herbivore Diictodon, the oldest known example of sexually dimorphic armament. Proceedings of the Royal Society B, 270, 173-178. 
TANOUE, K., YOU, H.-L. and DODSON, P. 2009. Comparative anatomy of selected basal ceratopsian dentitions. Canadian Journal of Earth Sciences, 46, 425-439.

LI, D. and YOU, H.-L. 2012. Tooth replacement pattern in maxillary dentition of basal Neoceratopsia. Bulletin of the Kitakyushu Museum of Natural History \& Human History Series A Natural History, 10, 123-127.

TEITELBAUM, S. L. 2000. Bone resorption by osteoclasts. Science, 289, 1504-1508.

TEMELES, E. J., PAN, I. L., BRENNAN, J. L. and HORWITT, J. N. 2000. Evidence for ecological causation of sexual dimorphism in a hummingbird. Science, 289, 441-443.

— MILlER, J. S. and RIFKIN, J. L. 2010. Evolution of sexual dimorphism in bill size and shape of hermit hummingbirds (Phaethornithinae): a role for ecological causation. Philosophical Transactions of the Royal Society B, 365, 10531063.

THOMAS, D. A. 2015. The cranial anatomy of Tenontosaurus tilletti Ostrom, 1970 (Dinosauria, Ornithopoda). Palaeontologia Electronica, 18, 1-99.

THORPE, R. S. 1989. Pattern and function of sexual dimorphism: a biometric study of character variation in the grass snake (Natrix natrix, Colubridae) due to sex and its interaction with geography. Copeia, 1989, 53-63.

THULBORN, R. A. 1971. Tooth wear and jaw action in the Triassic ornithischian dinosaur Fabrosaurus. Journal of Zoology, 164, 165-179.

1974. A new heterodontosaurid dinosaur (Reptilia: Ornithischia) from the Upper Triassic Red Beds of Lesotho. Zoological Journal of the Linnean Society, 55, 151-175.

- 1978. Aestivation among ornithopod dinosaurs of the African Trias. Lethaia, 11, 185-198.

VÄÄNÄNEN, H. K., ZHAO, H., MULARI, M. and HALLEEN, J. M. 2000. The cell biology of osteoclast function. Journal of Cell Science, 113, 377-381.

VOLLMERHAUS, B., ROOS, H., GERHARDS, H. and KNOSPE, C. 2003. Phylogeny, form and function of canine teeth in the horse. Anatomia, Histologia, Embryologia, 32, 212217.

WEISHAMPEL, D. B. and NORMAN, D. B. 1989. Vertebrate herbivory in the Mesozoic: jaws, plants, and evolutionary metrics. 87-100. In FARLOW, J. O. (ed.) Paleobiology of the dinosaurs. Geological Society of America, Special Paper, 238, 100 pp.

WESTERGAARD, B. and FERGUSON, M. W. 1987. Development of the dentition in Alligator mississippiensis: later development in the lower jaws of embryos, hatchlings and young juveniles. Journal of Zoology, 212, 191-222.

_ 1990. Development of the dentition in Alligator mississippiensis: upper jaw dental and craniofacial development in embryos, hatchlings and young juveniles, with a comparison to lower jaw development. American Journal of Anatomy, 187, 393-421.

WHITLOCK, J. A. and RICHMAN, J. M. 2013. Biology of tooth replacement in amniotes. International Journal of Oral Science, 5, 66-70.

WINGS, O. 2014. The rarity of gastroliths in sauropod dinosaurs: a case study in the Late Jurassic Morrison Formation, western USA. Fossil Record, 18, 1-16.

— and SANDER, P. M. 2007. No gastric mill in sauropod dinosaurs: new evidence from analysis of gastrolith mass and function in ostriches. Proceedings of the Royal Society B, 274, 635-640.

XU, X., MAKOVICKY, P. J., WANG, X. L., NORELL, M. A. and YOU, H.-L. 2002. A ceratopsian dinosaur from China and the early evolution of Ceratopsia. Nature, 416, 314-317.

FORSTER, C. A., CLARK, J. M. and MO, J. 2006. A basal ceratopsian with transitional features from the Late Jurassic of northwestern China. Proceedings of the Royal Society $B, 273,2135-2140$.

ZHENG, X.-T., YOU, H.-L., XU, X. and DONG, Z.-M. 2009. An Early Cretaceous heterodontosaurid dinosaur with integumentary structures. Nature, 458, 333-336. 